\title{
Electrolytes for high-energy lithium batteries
}

\author{
Jennifer L. Schaefer $\cdot$ Yingying Lu • \\ Surya S. Moganty $\cdot$ Praveen Agarwal • \\ N. Jayaprakash $\cdot$ Lynden A. Archer
}

Received: 8 October 2011/Accepted: 27 October 2011/Published online: 2 December 2011

(C) The Author(s) 2011. This article is published with open access at Springerlink.com

\begin{abstract}
From aqueous liquid electrolytes for lithiumair cells to ionic liquid electrolytes that permit continuous, high-rate cycling of secondary batteries comprising metallic lithium anodes, we show that many of the key impediments to progress in developing next-generation batteries with high specific energies can be overcome with cleaver designs of the electrolyte. When these designs are coupled with as cleverly engineered electrode configurations that control chemical interactions between the electrolyte and electrode or by simple additives-based schemes for manipulating physical contact between the electrolyte and electrode, we further show that rechargeable battery configurations can be facilely designed to achieve desirable safety, energy density and cycling performance.
\end{abstract}

Keywords Electrolytes - Lithium ion battery · Ionic liquids - Nanoparticle organic hybrids .

Lithium/air · Lithium dendrites

\section{Introduction}

Most commercial secondary/rechargeable lithium batteries are based on the lithium ion cell depicted in Fig. 1. A carbonaceous material such as graphite serves as the anode and hosts lithium as $\mathrm{LiC}_{6}$ in the charged state. A lithiated metal oxide (LiMO, e.g., $\mathrm{LiCoO}_{2}$ ) cathode hosts the lithium in the discharged state. The anode and cathode are coupled internally by a lithium ion-conducting, aprotic

J. L. Schaefer · Y. Lu · S. S. Moganty · P. Agarwal ·

N. Jayaprakash · L. A. Archer $(\square)$

School of Chemical and Biomolecular Engineering,

Cornell University, Ithaca, NY 14853-5201, USA

e-mail: 1aa25@cornell.edu organic ester or ether doped with a lithium salt [e.g., lithium hexafluorophosphate $\left.\left(\mathrm{LiPF}_{6}\right)\right]$. Shuttling of lithium ions between the anode and cathode produces an electric current in an external circuit that drives a desired load. To prevent electrode/electrode contact and short circuits, a porous polyolefin film (separator) is typically inserted between the electrodes. Since the early 1990s, lithium ion batteries based on this design have been the subject of intense scientific and commercial interest for portable electronics applications. In recent years, the demand for secondary batteries with higher operating voltages, improved cycling stability, higher power densities, enhanced safety, and lower initial and life cycle costs has increased to meet new needs for smaller, lighter, more powerful electronic devices, as well as to accommodate a growing interest in hybrid electric vehicles (HEV) and plug-in hybrid electric vehicles (PHEVs).

As illustrated in Fig. 2, the $\mathrm{LiC}_{6} / \mathrm{LiCoO}_{2}$ cell delivers one of the lowest specific energies of possible secondary battery configurations. Yet it remains attractive because this cell configuration offers superior energy densities, attractive operating voltages, lower self-discharge rates and a performance/cost structure that is competitive with the nickel metal hydride (NiMH) and other rechargeable battery configurations already in commercial use for HEVs. Additionally, even after taking into account the substantially lower practical specific energies of the $\mathrm{LiC}_{6} / \mathrm{LiCoO}_{2}$ ion battery (typically, only about $1 / 3$ of the maximum energy density is available in a fully packaged battery), this LIB configuration delivers a specific energy that exceeds the medium-term and comes close to the long-term goals set out by the US Advanced Battery Consortium (Miller 2009). Finally, all of the alternative cell configurations depicted in the figure, particularly those that offer exceptional specific energies, suffer from one or more 
Fig. 1 Schematic of a lithium ion battery during charge (left) and discharge (right)

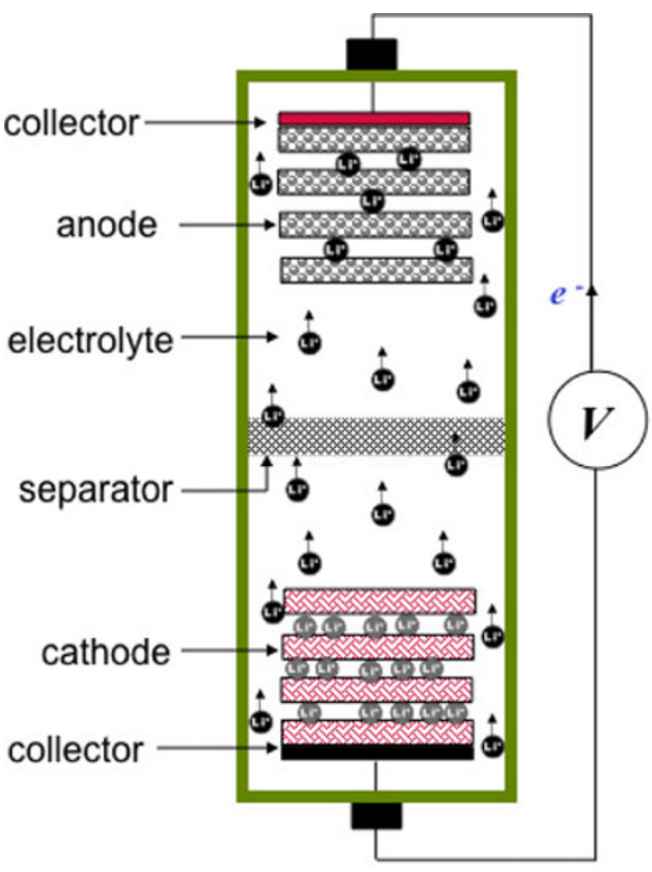

Charge

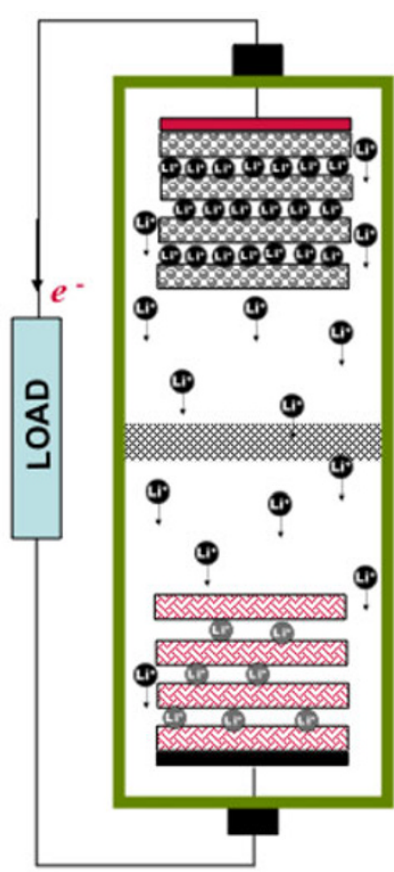

Discharge debilitating limitations, most involving the electrolyte, which prevent their widespread use. This review focuses on the modern search for electrolytes suitable for large-scale deployment in secondary lithium-based battery technologies that offer significantly improved performance and safety relative to the $\mathrm{LiC}_{6} / \mathrm{LiCoO}_{2}$-based platform.

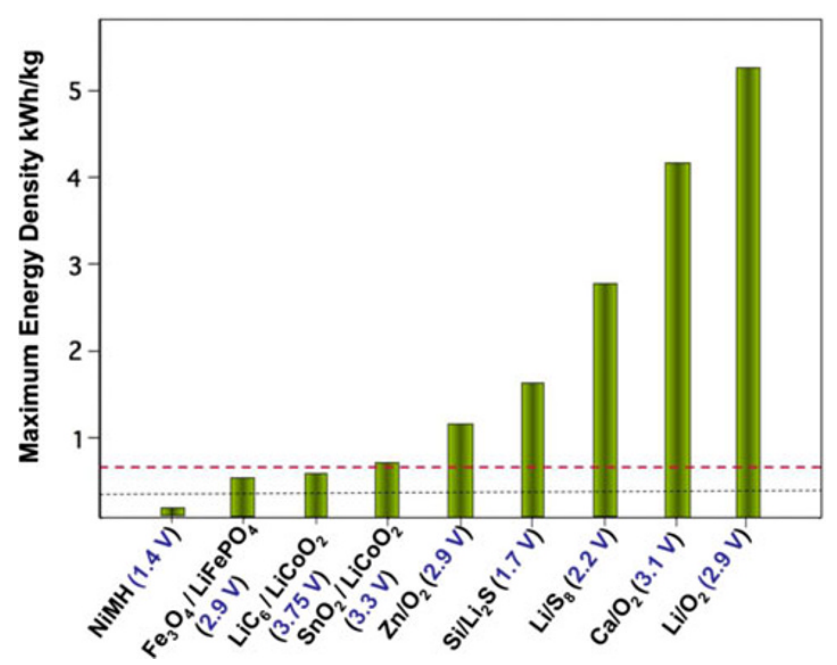

Fig. 2 Theoretical specific energy and open circuit potentials for various high-energy density secondary battery configurations. The specific energies for all of the metal/air battery configurations include the weight of oxygen. The horizontal lines are the USABC medium(black) and long-term (red) targets escalated by a factor of 3 to account for the typical factor of three reductions in energy density that occur when inert cell components (packaging, electrolyte, conductivity aid and current collectors) are included
A successful electrolyte is required to play multiple, critical roles in an electrochemical cell. First, it should isolate the electron and ion transport pathways in the cell. Second, it should promote ion-pair dissociation and selectively facilitate transport of the active ionic species (e.g., $\mathrm{Li}^{+}$ions in a lithium battery). Third, it must penetrate and wet the porous, chemically heterogeneous hybrid materials that constitute the electrodes and separator. Fourth, it should not leak, combust or vaporize during cell storage or operation. Fifth, it should be chemically robust in the presence of the electrodes and their redox products. Finally, it must itself be stable in the normal operating voltage range for the electrochemical cell. Significantly, these features must be maintained over thousands, even tens of thousands of charge-discharge cycles spanning many years of cell operation. Because it is rare for all six requirements to be met in a single material, the search for a successful electrolyte typically requires years of trial-anderror experimentation, including independent searches for suitable additives that might correct one or more shortcomings of an attractive material.

Organic esters and ethers, which have polar groups, are attractive as LIB electrolytes because they possess good affinity for lithium ions, moderate dielectric constants and moderate to low viscosities at room temperature (Fig. 3). Small Bjerrum lengths,

$l_{\mathrm{B}}=\frac{e^{2}}{4 \pi \varepsilon k T}$,

and attractive Stokes ion mobilities, 
$u_{i} \approx \frac{z_{i} e}{6 \pi a_{i} \eta}$

are also typical of these electrolytes under normal LIB operation conditions. Here, $e$ is the elementary charge; $\varepsilon$ is the dielectric constant of the medium; $k$ is Boltzmann's constant; $T$ the absolute temperature; $z_{i}$ and $a_{i}$ are, respectively, the valency and radius of ionic species " $i$ "; and $\eta$ is the viscosity of the medium. Thus, even a moderately large counterion (radius: $a_{-}>l_{\mathrm{B}}$ ) is sufficient to produce high levels of ion-pair dissociation from the compact lithium ions (radius: $a_{+}=0.076 \mathrm{~nm}$ ). The most common choices, ethylene carbonate (EC) coupled with a linear carbonate co-solvent-dimethyl carbonate (DMC), diethyl carbonate (DEC), ethylmethyl carbonate (EMC)and doped with $\mathrm{LiPF}_{6}$, also offer superior ionic conductivities to all alternatives: ionic liquids, polymers and ceramics. However, these electrolytes are volatile, flammable, leaky, display poor thermal stability, possess high reduction potentials (Fig. 3), and have narrow electrochemical stability windows and poor mechanical stability, which present obvious challenges for their large-scale deployment in batteries. Additionally, electrolytes based on organic ethers dissolve lithium polysulfides $\mathrm{LiS}_{\mathrm{x}}$, which erodes the cathode in high-energy lithium/sulfur and silicon/ $\mathrm{Li}_{2} \mathrm{~S}$ secondary batteries, and do not dissolve $\mathrm{Li}_{2} \mathrm{O}_{2}$, clogging the porous cathode in ultrahigh-energy density
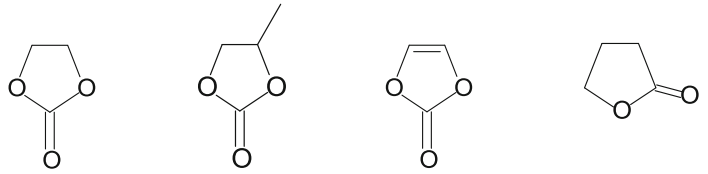

$$
\begin{array}{cc}
\mathrm{RP}=1.36 \mathrm{~V} & 1.00-1.60 \mathrm{~V} \\
\mathrm{OP}=6.2 \mathrm{~V} & 4.0-6.6 \mathrm{~V} \\
\mathrm{FP}=160^{\circ} \mathrm{C} & 132^{\circ} \mathrm{C} \\
\varepsilon=89.78 & 64.92 \\
\eta=1.90 \mathrm{cP}\left(40^{\circ} \mathrm{C}\right) & 2.53 \mathrm{cP} \\
\mathrm{EC} & \mathrm{PC}
\end{array}
$$$$
1.40 \mathrm{~V}
$$$$
73^{\circ} \mathrm{C}
$$$$
\text { VC }
$$
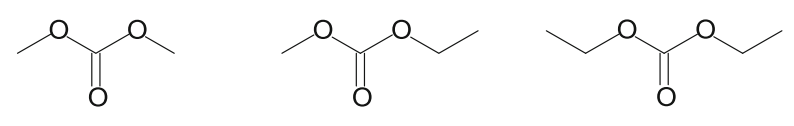

$$
\begin{gathered}
1.32 \mathrm{~V} \\
5.0-6.7 \mathrm{~V} \\
18^{\circ} \mathrm{C} \\
3.107 \\
0.59 \mathrm{cP}\left(20^{\circ} \mathrm{C}\right) \\
\mathrm{DMC}
\end{gathered}
$$

$6.7 \mathrm{~V}$
$27^{\circ} \mathrm{C}$
2.958
$0.65 \mathrm{cP}$
$\mathrm{EMC}$

$1.32 \mathrm{~V}$

$6.7 \mathrm{~V}$

$31^{\circ} \mathrm{C}$

2.805

$0.75 \mathrm{cP}$

DEC
Fig. 3 Chemical structures of common liquid electrolyte components and their properties. $R P$ reduction potentials [as reported by Yoshio et al. (2009)], $O P$ oxidation potentials (as summarized from $\mathrm{Xu}^{3}$ ), $F P$ flash point, $\varepsilon$ dielectric constant at $25^{\circ} \mathrm{C}, \eta$ viscosity at $25^{\circ} \mathrm{C}$ unless otherwise noted lithium-air batteries (Fig. 2), making them incompatible with the most energy-dense lithium battery platforms.

Efforts to manage and/or ameliorate the most serious problems with aprotic organic electrolytes are extensive and nicely documented in several excellent reviews (Zhang 2006; Xu 2004; Verma et al. 2010; Aurbach et al. 2007; Yoshio et al. 2009; Scrosati and Garche 2010). It is now understood, for example, that because the potential at either LIB electrode decays over a distance of the order of the Debye length,

$l_{\mathrm{D}}=\left(\frac{\varepsilon_{0} \varepsilon_{r} k T}{\left(n_{+}^{2}+n_{-}^{2} z_{-}^{2}\right) e^{2}}\right)^{1 / 2}$,

the high relative electrolyte permittivity, $\varepsilon_{r}$, and salt concentrations, $\left(n=n_{+}+n_{-}: O(1 M)\right)$, typically employed to insure high ionic conductivities, also mean that the electrolyte in the vicinity of the electrode is subjected to large potential gradients; $\varepsilon_{0}$ is the permittivity of the vacuum and $n_{i}$ is the molar concentration of the unassociated ionic species $i$ in solution. Thus, even under moderate cell potentials where the pure electrolyte may be nominally stable, it will degrade continuously when in contact with either electrode. Several studies have shown that the degradation product is an electrically insulating but ionically conducting polymer, and that its thickness and porosity can be controlled (by introducing additives to the electrolyte and/or by initially cycling the cell at a low rate) to create a passivating coating that slows/stops subsequent electrolyte degradation (Aurbach et al. 2007; Yoshio et al. 2009; Scrosati and Garche 2010). This benefit is perhaps intuitive, since an electronically insulating polymer coating of any thickness reduces the magnitude of the potential gradients at the solid electrolyte interface (SEI). Numerous approaches for controlling the SEI in Li-ion batteries employing aprotic organic electrolytes have been reported; we will review the most recent methods at the end of "Liquid electrolytes for high-energy batteries" of the study.

The review is organized as follows. We report on the progress in development and characterization of novel liquid electrolyte systems for high-energy density lithium batteries in "Liquid electrolytes for high-energy batteries". This is followed by "Solid-state electrolytes: ceramics, polymers, composites, and hybrids", in which we review progress on solid-state electrolytes based on ceramics and polymers. Finally, in "mixed phase electrolytes", we discuss mixed phase solid-liquid electrolytes.

\section{Liquid electrolytes for high-energy batteries}

Aqueous electrolytes for lithium batteries

Aqueous electrolytes preserve many of the advantages of aprotic liquid electrolytes, but provide an environmentally 
friendly, non-flammable, low cost solution for some of their shortcomings. Until recently, the narrow electrochemical stability window of liquid water $(1.23 \mathrm{~V})$ and its reactivity with metallic electrodes prevented its successful implementation in lithium batteries. Lou et al. recently reported results from a detailed study of the reactivity of various electrode materials in aqueous electrolytes (Luo et al. 2010). These authors showed that by manipulating the $\mathrm{pH}$ of the electrolyte, it was possible to shift the electrochemical stability window. Further, they demonstrated that if dissolved oxygen was eliminated and carbon-coated electrodes employed, aqueous lithium ion batteries based on materials such as $\mathrm{LiTi}_{2}\left(\mathrm{PO}_{4}\right)_{3} / \mathrm{LiFePO}_{4}$ could be cycled at a rate of $1 \mathrm{C}$ to yield a specific energy of $50 \mathrm{~W} \mathrm{~h} \mathrm{~kg}^{-1}$ based on the total weight of the electrode materials. This energy density is competitive with lead-acid and $\mathrm{Ni}-\mathrm{Cd}$ batteries. However, the aqueous lithium ion battery offers a much higher power density, retaining $80 \%$ of the reversible capacity when the rate is increased to 10C. Furthermore, the battery manifested over $90 \%$ capacity retention over 1,000 charge/discharge cycles.

The benefits of aqueous electrolytes for lithium batteries are even more markedly evident for Li-air batteries (Zhou et al. 2010; Girishkumar et al. 2010). As illustrated in Fig. 2, the theoretical specific energy of the lithium/air battery (including the oxygen cathode) is $5.2 \mathrm{kWh} / \mathrm{kg}$. Most designs utilize a porous/open carbon cathode configuration designed to facilitate continuous re-supply of oxygen from the surroundings and therefore potentially offer substantially higher specific energies, $11 \mathrm{~kW} \mathrm{h/kg}$. These values are comparable to typical energy densities for coal, $6.7 \mathrm{~kW} \mathrm{~h} / \mathrm{kg}$, and are only marginally lower than the specific energy of commercial-grade gasoline, $12 \mathrm{~kW} \mathrm{h/kg}$. Works on Li-air batteries employing aqueous electrolytes rely upon the high solubility of $\mathrm{Li}_{2} \mathrm{O}_{2}$ in water to avert problems with premature fouling of the porous cathode, but achieve this effect by employing decidedly different approaches for protecting the metallic lithium anode from water. The all-aqueous Li-air battery utilizes an inert ceramic solid-state electrolyte coating on the anode, which protects it from water, but is sufficiently conductive for $\mathrm{Li}^{+}$ions to facilitate the shuttling reaction. In the mixed electrolyte $\mathrm{Li}$-air battery configuration proposed by Zhou et al. (2010), the anode and porous cathode are separated by a water-impermeable, lithium ionconductive membrane (e.g., LISICON). The cathode is in contact with the aqueous electrolyte, and the metallic lithium anode is in contact with an aprotic liquid electrolyte. The primary advantage of these designs is that the cathode is submerged in water and the discharge reaction product is soluble in water, so this eliminates problems of cathode clogging, expansion and electrical conductivity that result from the use of an aprotic electrolyte. Wang and Zhou (2010) reported cathode capacities of 50,000 mAh/g (based on the total mass of porous catalytic electrode) when the $\mathrm{Li}-$ air cells were cycled at a low rate $(100 \mathrm{mAh} / \mathrm{g})$.

\section{Electrolytes for secondary lithium-sulfur batteries}

As illustrated in Fig. 2, the $\mathrm{Li}-\mathrm{S}$ and $\mathrm{Si}-\mathrm{Li}_{2} \mathrm{~S}$ secondary batteries provide among the highest specific energies of lithium-based cells. Sulfur, the active material used in both cathode configurations, is inexpensive, abundant and nontoxic. Early reports showed that $\mathrm{Li} / \mathrm{S}$ cells with organic liquid electrolytes displayed poor cycle life and low Columbic efficiencies. Cycling of a sulfur cathode results in the formation of various lithium polysulfides such as $\mathrm{Li}_{2} \mathrm{~S}$, $\mathrm{Li}_{2} \mathrm{~S}_{2}, \mathrm{Li}_{2} \mathrm{~S}_{3}$ and $\mathrm{Li}_{2} \mathrm{~S}_{4}$ (Ryu et al. 2005; Chang et al. 2002; Yamin et al. 1988). These polysulfides are soluble in the typical aprotic carbonate liquid electrolytes, resulting in dissolution/erosion of the cathode by the electrolyte upon cycling. The resultant fall-off/fading of the cathode capacity presents a significant barrier for successful implementation of sulfur cathodes.

Many investigations have focused on combinations of liquid electrolytes, as well as of electrolytes and additives, which display various levels of success in reducing polysulfide dissolution while still demonstrating sufficient ionic conductivity, safety and electrochemical stability. For example, tetrahydrofuran (THF) (Hamlen et al. 2001), 1,3dioxolane (DOXL) (Chang et al. 2002; Wang et al. 2010a; Jin et al. 2003), dimethoxy ethane (DME), carbonates (Wang et al. 2003, 2004a) and polyethylene glycol dimethyl ethers (PEGDME) (Ryu et al. 2005; Wang et al. 2010a; Choi et al. 2008; Cheon et al. 2003a, b; Ryu et al. 2006a) have been investigated. Among these electrolytes, tetra(ethylene glycol)dimethyl ether (TEGDME), a dimethyl terminated polyethylene oxide oligomer, has been found to be particularly attractive. Without any efforts to modify the cathode, Li/S cells employing TEGDME-based electrolytes have been shown to provide specific capacities over 1,200 $\mathrm{mAh} / \mathrm{g}$ during the first charge at room temperature (Chang et al. 2002; Hamlen et al. 2001; Ryu et al. 2006a, b). Choi et al. $(2007,2008)$ reported on the performance of TEGDME/1 $\mathrm{M} \mathrm{LiCF}_{3} \mathrm{SO}_{3}$ electrolyte solution, which they compared with a variety of other electrolyte formulations. Significantly, a cell employing a solution of 5 vol.\% toluene in TEGDME was reported to maintain a discharge capacity of $533 \mathrm{mAh} / \mathrm{g}$ following 50 cycles at a low rate $(1 / 16 \mathrm{C})$ and exhibited near stable impedance spectra on cycling.

Mikhaylik and Akridge (2003) and Ryu et al. (2006a) both show that the performance of TEGDME electrolytes in $\mathrm{Li} / \mathrm{S}$ cells is markedly worse at low temperatures. By adding 1,3-dioxolane (DOXL) and methylacetate (MA) to the TEGDME electrolyte in the ratio of MA:DOXL:TEGDME_-5:47.5:47:5, by volume-Ryu et al. observed that 
Fig. $4 \mathrm{Li} / \mathrm{S}$ secondary battery based on S@C composite and PEGME/LiTFSI electrolyte.

a Transmission electron micrograph of sulfur infused mesoporous, hollow carbon particles. b Cyclic voltammetry data for S@C at a scan rate of $0.2 \mathrm{mV} / \mathrm{s}$. Results are for the 2nd and 50th cycle. c First discharge voltage profiles for $\mathrm{Li} / \mathrm{S}$ at various discharge rates. d Specific discharge capacity versus cycle number for $\mathrm{Li} / \mathrm{S}$ cell at a fixed discharge rate of $0.5 \mathrm{C}$
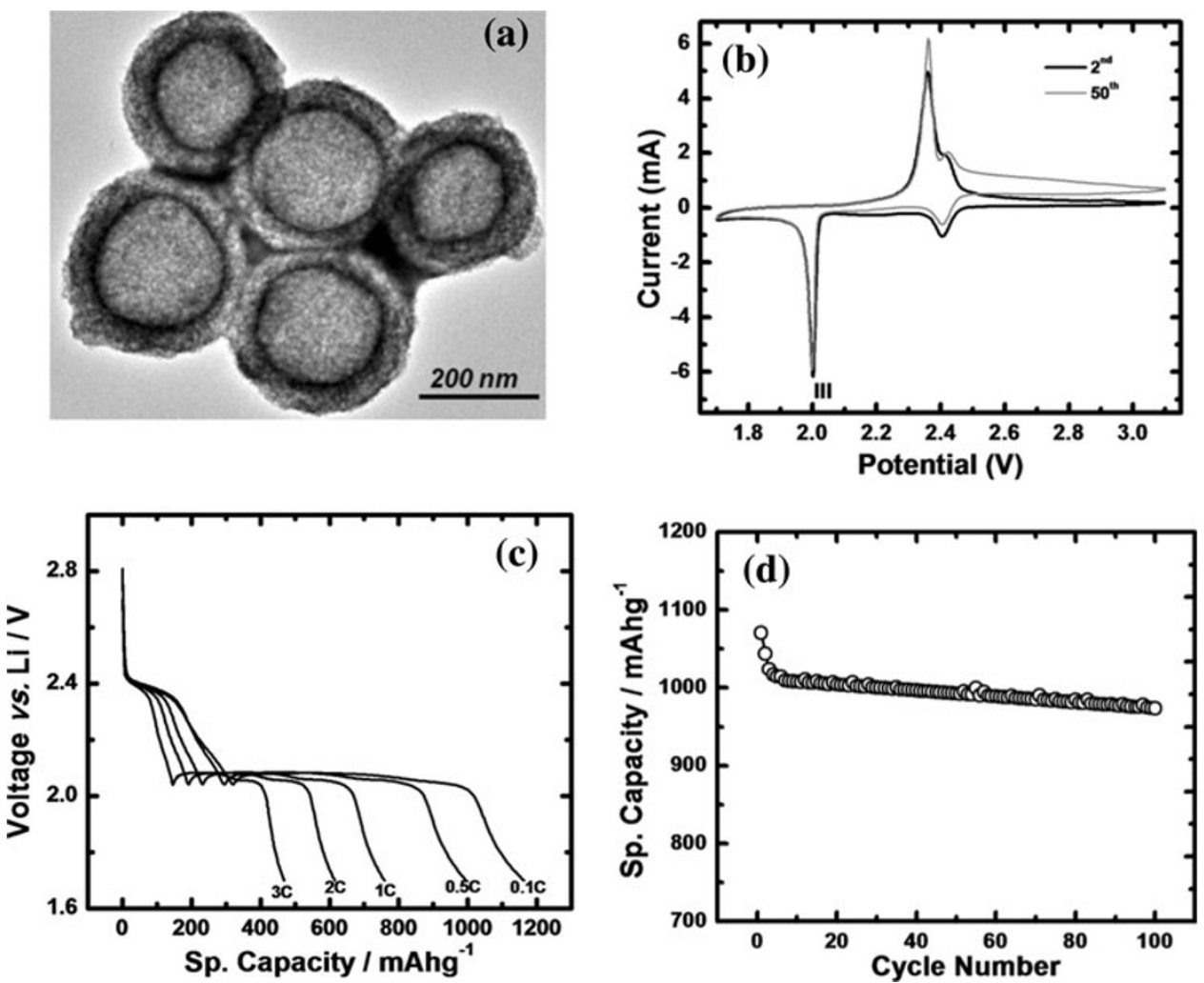

the first discharge capacity could be significantly improved to $994 \mathrm{mAh} \mathrm{g}^{-1}$ at $-10^{\circ} \mathrm{C}$ from $357 \mathrm{mAh} / \mathrm{g}$. Shin and Cairns (2008) showed that Li/S cells could be successfully cycled with an electrolyte mixture of PEGDME $\mathrm{M}_{n}=250$ and 1-butyl-1-methylpyrrolidinium bis(trifluoromethanesulfonyl)imide (C4mpyr TFSI) ionic liquid. The addition of PEGDME to the ionic liquid was found to reduce its viscosity and enhance ionic conductivity to $4.2 \times 10^{-3} \mathrm{~S} / \mathrm{cm}$ at $29^{\circ} \mathrm{C}$. When cycled at room temperature and at low rates, the Li/S cell with C4mpyr TFSI-0.5 M LiTFSI-2 PEGDME electrolyte maintained a discharge capacity of $269 \mathrm{mAh} / \mathrm{g}$ after 100 cycles; however, the cells exhibited poor performance at lower temperatures. Cells containing pure C4mpyr-LiTFSI electrolyte, without PEGDME, exhibited poor cycling performance at all temperatures due to polysulfide dissolution.

Recently, several studies have reported that encapsulation of the sulfur into a porous carbon framework wetted by the electrolyte can significantly improve performance of $\mathrm{Li} / \mathrm{S}$ batteries. Ji et al. (2009), for example, showed that $\mathrm{Li} / \mathrm{S}$ cells based on a nanocomposite cathode, created by wicking molten sulfur into a conductive, mesoporous carbon framework and an electrolyte comprising 1.2 $\mathrm{M} \mathrm{LiPF}_{6}$ solution in ethyl methyl sulfone, could be cycled at moderate rates $(\sim 0.2 \mathrm{C})$ to yield specific capacities exceeding $800 \mathrm{mAh}^{-1}$, with some capacity fade after 20 cycles. When a layer of polyethylene glycol was appended to the particles, the authors reported that the Li/S cell capacity improved noticeably, to above $1,100 \mathrm{mAh} / \mathrm{g}$, and that the cells showed no evidence of the capacity fade after 20 charge/discharge cycles. Figure 4 reports results from a more recent study by Jayaprakash et al. (2011), which employed a high-pressure method to infuse sulfur sublimate in the vapor phase into mesoporous, hollow carbon particles (Fig. 4a) synthesized by high-temperature calcination of petroleum pitch. Cyclic voltammetry measurements (Fig. 4b) of Li/S cells employing these S@C composite materials and an electrolyte comprising $1 \mathrm{M}$ lithium bis (trifluoromethane sulfone) imide (LiTFSI) in TEGDME indicate stable electrochemical performance after 50 cycles. Figure 4c shows the first-cycle voltage profile of the material during galvanostatic cycling at low (0.1C) as well as high (3C) charge rates. Figure $4 d$ reports the discharge capacity based on the active sulfur, which comprises $70 \mathrm{wt} \%$ of the $\mathrm{S} @ \mathrm{C}$ composite, measured at a rate of $0.5 \mathrm{C}$. Although small levels of capacity fading is evident in Fig. 4d, these results attest to the electrochemical stability of the composite sulfur@carbon cathode material in the TEGDME-based electrolyte.

Electrolytes based on ionic liquids

One of the most straightforward changes that can be made within the current $\mathrm{LIB}$ framework $\left(\mathrm{LiMO} / \mathrm{LiC}_{6}\right)$ to increase specific energies is to increase the $\mathrm{Li}$ ion insertion potential at the cathode. Cathodes based on $\operatorname{LiM}_{0.5} \mathrm{Mn}_{1.5} \mathrm{O}_{4}$ or 


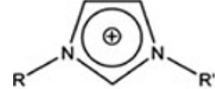

Imidazolium

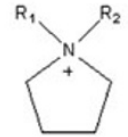

Pyrrolidinium

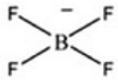

Hexafluorophosphate $\left(\mathrm{PF}_{6}\right)$

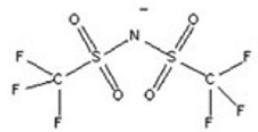

Bis(trifluoromethanesulfonyl)imide (TFSI)

Fig. 5 Chemical structures of representative cations and ions used for ionic liquid electrolytes

$\mathrm{LiMMnO}_{4}$ spinels, where $\mathrm{M}$ is a divalent or trivalent metal (e.g., copper, nickel, iron, cobalt, chromium), can form the basis of LIBs with open circuit potentials close to, or even exceeding, $5 \mathrm{~V}$ (Todorov et al. 1999). Unfortunately, none of the currently used aprotic liquid electrolytes can be safely used at such high cell potentials. High-temperature molten salts (liquid oxides, silicates, etc.) have been studied for a long time (Terada et al. 2001) and have been speculated for some time as potential LIB electrolytes for high-voltage cells. Typical cation and anion structures that are suitable for creating ILs are depicted in Fig. 5. Unlike molten salts, room-temperature ionic liquids (ILs) are organic salts having melting points below $100^{\circ} \mathrm{C}$ (Bennemann et al. 1982). The earliest IL, ethyl-ammonium nitrate, was synthesized in 1914 with a melting point of $12^{\circ} \mathrm{C}$ (Hussey 1983; Walden 1914). A few ionic liquids were later developed for electroplating (Zhao and Van der Noot 1997), catalysis (Welton 1999) and organic synthesis. Wilkes and Zaworotko (1992) developed air- and waterstable low melting point tetrafluoroborate ionic liquids.

ILs exhibit many interesting properties, including ultra low vapor pressure, good thermal stability, wide range of solubility of organic and inorganic compounds, high polarity and non-coordinating nature, hydrophilic and lipophilic nature, high ionic conductivity, wide electrochemical stability windows and tunability, which make them attractive as battery electrolytes (Wasserschied and Welton 2003; Davis 2004; Ohno 2005). Among the large number of possible IL configurations, imidazolium- and pyrrolidinium-based ILs are most widely studied for their potential as next-generation $\mathrm{Li}$ ion battery electrolytes. The inherent robustness of the cation and anion of IL plays a

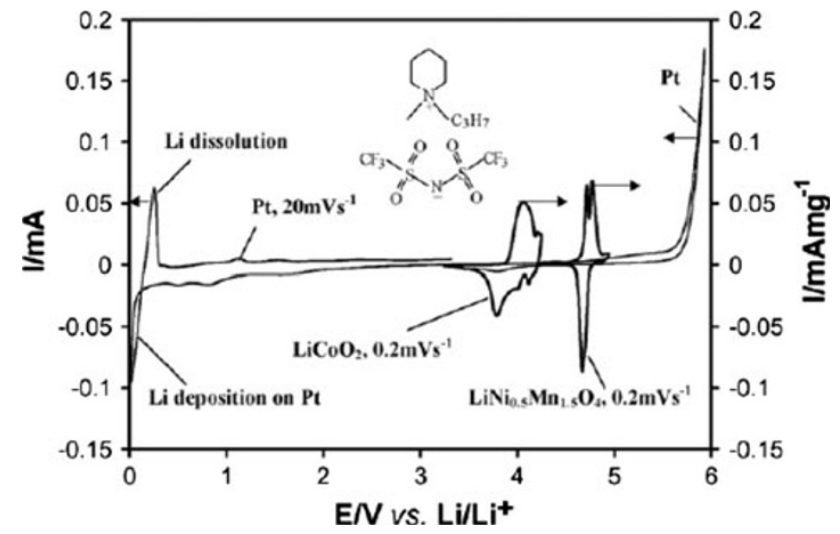

Fig. 6 The electrochemical stability window of 0.5 M LiTFSI in an $N$-methyl- $N$-propylpiperdinium bis(trifluoromethanesulfonyl)imide electrolyte solution measured on a $\mathrm{Pt}$ electrode and cyclic voltammograms of $\mathrm{LiCoO}_{2}$ and $\mathrm{LiNi}_{0.5} \mathrm{Mn}_{1.5} \mathrm{O}_{4}$ spinel electrodes as indicated in the reprint from Martha et al. (2009), with permission from Elsevier

vital role in dictating the overall redox stability of the IL (Moganty et al. 2009). Imidazolium-based ILs exhibit stability window of about $4 \mathrm{~V}$ and other cyclic aminebased ILs, pyrrolidinium and piperdinium cations, show stability limits of about $6 \mathrm{~V}$ (Fig. 6) (Martha et al. 2009; Lewandowski and Swiderska-Mocek 2009; Lewandowski and Swiderska-Mocek 2010). Imidazolium-based cations suffer from cathodic instabilities. Improvements in this area were demonstrated by Seki et al. (2006), whereas a ring substitution allowed for improved cycling efficiency against lithium metal. High stability windows have been reported for ILs containing TFSI anion (Borgel et al. 2009).

High lithium ion conductivity is a desirable characteristic for Li ion battery electrolytes. The total ionic conductivities of ILs range from $10^{-4}$ to $10^{-2} \mathrm{~S} / \mathrm{cm}$ at room temperature (Moganty et al. 2009; Goodenough and Kim 2010). Imidazolium-based ILs show comparatively higher values of conductivities than pyrrolidinium-based ILs. Irrespective of the type of cation and anion, addition of $\mathrm{Li}$ salt to the IL decreases the overall ionic conductivity due to an increase in viscosity and the formation of ionic clusters with $\mathrm{Li}^{+}$. The effect of $\mathrm{Li}$ salt concentration on 1-2dimethyl-3-propyl imidazolium bis(trifluoromethyl sulfonyl)imide IL electrochemical properties, such as ionic conductivity, viscosity and interfacial resistances at the $\mathrm{LiCoO}_{2}$ and Li metal interfaces, was studied by Seki et al.; they found that an optimum $\mathrm{Li}$ salt concentration existed for high-rate performance batteries (Seki et al. 2007). Appectecchi et al. (2009) found that increase in alkyl chain length resulted in decrease in ionic conductivity of $\mathrm{N}$-alkyl$N$-methylpyrrolidinium bis(trifluoromethylsulfonyl)imide ILs. Tokuda et al. (2004) investigated the effect of anion on the physicochemical properties of 1-butyl-3-methylimidazolium cation-based ILs. They concluded that the molar 
conductivity ratio has the following order in the IL anions studied: hexafluorophosphate $\left(\mathrm{PF}_{6}\right)>$ tetrafluoroborate $\left(\mathrm{BF}_{4}\right)>$ bis (pentafluoroethylsulfonyl) imide (BETI) > bis(trifluoromethylsulfonyl)imide (TFSI) $>$ trifluoromethanesulfonate $(\mathrm{TfO})>$ trifluoroacetate $(\mathrm{TFA})$. The observed trend is related to the anionic characteristics such as charge delocalization and fluorine content, where a higher molar conductivity ratio is found for ILs that dissociate more readily. While ionic liquids display high total ionic conductivities, they exhibit low lithium transference numbers and thus lower lithium ion conductivity when compared with other liquid electrolytes. Addition of neutral molecules such as vinylene carbonate, tetrahydrofuran, ethylene carbonate and toluene have been reported by MacFarlane and coworkers to significantly change transport properties of $\mathrm{N}$-ethyl- $\mathrm{N}$-propylpyrrolidinium bis(trifluoromethane sulfonyl)imide (Bayley et al. 2009). The chemical identity and donor ability of diluents play a major role in enhancing the $\mathrm{Li}$ ion transport properties of LiTFSI solutions of IL.

Lee et al. (2006) reported synthesis and electrochemical characterization of a series of ILs with methyl acetate moiety. These ILs exhibited large redox stabilities and high ionic conductivities, with an increase in conductivity in the presence of $\mathrm{Li}$ salt due to the interaction between $\mathrm{Li}^{+}$and the ester group on the cation of the ILs. Similarly, Egashira showed the improved properties of the quaternary ammonium-based ILs containing cyano functional groups (Egashira et al. 2004). Most recently, Hussey and coworkers designed and synthesized a series of piperdinium cation-based ILs with a propylene carbonate (PC) moiety that showed favorable electrochemical characteristics for Li metal batteries (Tsuda et al. 2011).

Some ionic liquids, such as 1-butyl-1-methylpyrrolidinium bis (trifluoro methanesulfonyl) imide (C4mpyr TFSI) with LiTFSI (Howlett et al. 2004, 2006; Liu et al. 2010; Bhatt et al. 2010; Lane et al. 2010), have been shown to enhance uniform deposition on the lithium metal anode, thus reducing dendrite formation without additional additives. This opens up the way for the highest energy density lithium batteries of all: those employing metallic lithium as anode. The improved lithium plating behavior of (C4mpyr TFSI) doped with LiTFSI is thought to occur due to formation of crystalline-like liquid layers at the interface with the crystalline electrode (Valencia et al. 2002). This phenomenon is not understood, and varying effects are seen experimentally with chemical changes to the plating substrate or electrolyte.

The tunability of ILs evidently offers a spectrum of opportunities to modify the properties required for successful preparation of next-generation Li battery electrolytes that are non-volatile, non-flammable and thermally stable at high temperatures. Significant challenges exist in developing ionic liquids with sufficiently high lithium ion conductivity that also function well with high-energy storage capacity electrodes, such as sulfur and lithium metal. However, the recent upsurge of broad-based interest in ILs leads us to the perhaps hopeful conclusion that in a matter of years, IL electrolyte configurations suitable for the most energy-dense batteries of all (metal-air cells) will be found.

Additives for aprotic liquid electrolytes

Easily polymerizable electrolyte additives, such vinylene carbonate (VC) and catechol carbonate, have been shown to be particularly effective in producing stable SEI coatings on $\mathrm{LiC}_{6}$ and $\mathrm{LiCoO}_{2}$ (El Ouatani et al. 2009; Oesten et al. 2002). Their use results in very small irreversible capacity loss upon SEI creation without sacrifices in the stability of electrodes or ionic conductivity, thus extending the life cycle of lithium ion cells. The discharge capacity and cycling performance of PC-based electrolytes containing butyl sultone (BS) have been studied by Xu et al. (2007). These authors showed that BS rapidly formed a protective film on the graphite electrode and improved room-temperature battery performance. Other sulfones, including 1 , 3-propane sultone (PS) (Park et al. 2009), have been used as additives in LIBs employing mixed carbonate electrolytes EC/DEC/DMC-1 M PF 6 electrolyte. Significantly, when paired with another SEI additive, succinic anhydride (SA), Lee et al. showed that PS additives were suitable for stabilizing a mixed 1:2 EC/EMC-1 $\mathrm{M} \mathrm{LiPF}_{6}$ electrolyte in $\mathrm{LiNi}_{0.5} \quad \mathrm{Mn}_{1.5} \mathrm{O}_{4} /$ graphite $5 \mathrm{~V}$ cells (Chen et al. 2007). Butylene sulfite has recently been shown to be a good SEI additive for PC-based electrolytes employed in both highvoltage, $\mathrm{LiMn}_{1.99} \mathrm{Ce}_{0.01} \mathrm{O}_{4}$ /graphite and high-power, $\mathrm{LiFe}$ $\mathrm{PO}_{4} /$ graphite electrodes (Yao et al. 2009).

Another approach proposed by Menkin et al. (2009) employs a pre-formed, artificial SEI to stabilize the interface. These authors used electropainting and vacuuminsertion techniques to deposit a polymer based on poly(ethylene-co-acrylic acid) and carboxymethylcellulose on graphite as well as $\mathrm{Sn}-\mathrm{Cu}$ composite anode. They showed that the artificial SEI produced close to a fivefold improvement in the cycling performance of the battery. Likewise, Song (Song and Baek 2009) employed Fourier transform infrared spectroscopy to show that trimethoxy methylsilane spontaneously polymerized on a metallic $\mathrm{Si}$ anode in an EC/DC (1:1) electrolyte. These authors reported capacities of $2,400 \mathrm{mAh} / \mathrm{g}$ for over 200 charge/ discharge cycles. An even more dramatic illustration of this concept comes from the study by Lee et al. (2007), which investigated the effect of triacetoxyvinylsilane (VS) on the surface morphology of a metallic lithium electrode cycled at $1.25 \mathrm{~mA} \mathrm{~cm}^{-2}(\mathrm{C} / 2)$ in $1: 1 \mathrm{EC} / \mathrm{DMC}-1 \mathrm{M} \mathrm{PF}_{6}$ with varying VS content. Remarkably, these authors showed 
that an electrolyte containing $2 \mathrm{wt} \%$ VS minimized the formation of lithium dendrites and maintained $80 \%$ of the initial capacity after 200 cycles in the $\mathrm{LiCoO}_{2} / \mathrm{Li}$ cell.

The flammability of aprotic liquid electrolytes represents another significant threat to their large-scale deployment, particularly in large secondary batteries (Balakrishnan et al. 2006). Flame retardant (FR) additives aim to reduce this threat while maintaining good ionic conductivity and cycling characteristics. Most FRs act by chemical radical scavenging, which terminates the radical chain combustion reaction (Wang et al. 2001). Ideally, the amount of FR should be kept below 20 vol.\%, to minimize the deleterious effects on battery performance (Arai 2003); however, ignition under high pressure of oxygen or other kinds of abuse conditions is still possible with the highly flammable linear carbonate solvents in this range. Organic phosphates (alkyl phosphates and aryl phosphates) (Mandal et al. 2006), halogens, biphenyls, their combination or derivatives (Jow et al. 2005), and nitrogen-containing compounds are by far the most common FRs. Hyung et al. (2003) investigated a group of organic phosphate compounds, triphenylphosphate (TPP) and tributylphosphate (TBP) and found that they markedly improved the thermal stability of lithium-based cells. Shigematsu et al. (2009) found that in a C/VEC-VC-LiPF $6 \mathrm{Li}_{\mathrm{x}} \mathrm{CoO}_{2}$ cell, trimethyl phosphate (TMP) promotes thermal stability of both electrodes. Morita et al. (2005) showed that TMP perhaps achieves this benefit by preventing thermal decomposition of $\mathrm{LiPF}_{6}$. Cresyl diphenyl phosphate (CDP) FRs have been studied by Shim et al. (2009), as well as by Zhou et al. (2008). Both groups showed that the thermal stability and non-flammability of aprotic liquid electrolytes can be markedly improved by adding only $5 \mathrm{wt} \%$ CDP. Zhang et al. (2009) reported a new flame retardant called vinyl-tris-(methoxydiethoxy)silane (VTMS). Their combustion tests revealed that the addition of VTMS at 5-15 vol.\% could dramatically reduce the flammability of a $1 \mathrm{M} \mathrm{LiPF}_{6}$-EC/EMC/DMC $(1: 1: 1, \mathrm{v} / \mathrm{v} / \mathrm{v})$ electrolyte. Recently, Fei and Allcock (2010) reported that a PC electrolyte containing methoxyethoxyethoxy phosphazene oligomers and the corresponding high molecular weight polymer simultaneously exhibited attractive flame retardance and good ionic conductivity.

\section{Solid-state electrolytes: ceramics, polymers, composites and hybrids}

All solid-state batteries have some inherent advantages over liquid electrolytes, namely no chance of electrolyte leakage and reduced flammability. They also allow for the implementation of advanced battery architectures and the possibility of safe implementation of rechargeable, highenergy density batteries employing lithium metal anodes by mechanical inhibition of lithium dendrite formation that can cause cell short-circuiting. However, the ionic conductivity of dry cells is often less, especially at room temperature, than that of liquid cells. Current studies in the solid-state electrolyte field aim to mitigate losses in ionic conductivity, and therefore cell rate capability, while still improving safety and efficient cycling behavior.

\section{Ceramic electrolytes}

Ceramic electrolytes are non-flammable and thermally stable to high temperatures. They are also mechanically strong: nanoindentation measurements of lithium phosphonate oxide (LiPON) demonstrate elastic modulus of $77 \mathrm{GPa}$, (Herbert et al. 2011), which is well beyond the minimum value of 3.4 GPa predicted by Newman (Monroe and Newman 2009) that is required of an electrolyte to suppress metallic lithium dendrite formation. Despite their mechanical strength, many ceramic electrolytes demonstrate excellent room-temperature ionic conductivity $\left(>10^{-3} \mathrm{~S} / \mathrm{cm}\right)$ with lithium transference $\sim 1$. Fergus (2010) recently published a comprehensive review of ionic conductivity data for ceramic and polymer electrolytes, which provides an excellent comparison of the ionic conductivity of the three main classes of ceramic electrolytes-sulfides, oxides and phosphates. Another review by Patil et al. (2008) provides a comprehensive history of thin film battery development, including ceramic electrolytes, through 2008. It is important to note that while many ceramics exhibit ionic conductivity of the order of $10^{-3} \mathrm{~S} / \mathrm{cm}$ at room temperature, it is LiPON with an ionic conductivity of only $2 \times 10^{-6} \mathrm{~S} / \mathrm{cm}$ that has had gained widespread use, suggesting that other properties play an important role in the success of the electrolyte. Vacuum-sputtered LiPON is an amorphous ceramic with a wide electrochemical stability window $(5.5 \mathrm{~V}$ vs. $\mathrm{Li})$, interfacial stability in contact with metallic lithium, thermal stability up to $300^{\circ} \mathrm{C}$, and an ionic conductivity which is acceptable for use in a thin film battery with micron-scale (or thinner) electrolyte thickness (Yu et al. 1997).

Solid-state batteries utilizing ceramic electrolytes can exhibit high interfacial impedances, as some ceramics, including many sulfides, react with common anode and cathode chemistries such as $\mathrm{LiCoO}_{2}$. Since reactivity of a pair of electrolyte-electrode materials is not always obvious, interfacial impedance characterization must be performed. For example, one report showed that a stable SEI formed between an alloy $\mathrm{Li}-\mathrm{Al}$ anode and thio-LISICON type electrolytes with compositions $\mathrm{Li}_{3.4} \mathrm{Si}_{0.4} \mathrm{P}_{0.6} \mathrm{~S}_{4}$ and $\mathrm{Li}_{3.25} \mathrm{Ge}_{0.25} \mathrm{P}_{0.75} \mathrm{~S}_{4}$ and activation energies at the interface smaller or comparable to those reported for a lithium metal/ composite polymer electrolyte interface (Kobayashi et al. 2008). However, $\mathrm{Li}_{3} \mathrm{PO}_{4}-\mathrm{Li}_{2} \mathrm{~S}-\mathrm{SiS}_{2}$ and thio-LISICON 
$\mathrm{Li}_{3.325} \mathrm{P}_{0.935} \mathrm{~S}_{4}$ electrolytes reacted continuously with the Li-Al anode. Takahara has reported decomposition at the $\mathrm{Li}_{3} \mathrm{PO}_{4}-\mathrm{Li}_{2} \mathrm{~S}-\mathrm{SiS}$ and $\mathrm{Li}$ metal interface (Takahara et al. 2004). Electronic conductivity of perovskite type of lithium lanthanum titanate oxide (LLT) is enhanced significantly by contact with metallic lithium due to $\mathrm{Ti}^{4+}$ reduction (Kotobuki et al. 2010a). Oxide impurities form at the interface of LLT and $\mathrm{LiCoO}_{2}$ cathode with sintering, creating high interfacial resistance that dominates cell behavior, while $\mathrm{LiMnO}_{4}$ was shown to form a low resistance interface with LLT. Similarly, the formation of the inert oxide layer increases the $\mathrm{LiNi}_{0.5} \mathrm{Mn}_{0.5} \mathrm{O}_{2} / \mathrm{LATSP}$ interfacial resistance, blocking the Li ion diffusion through the interface (Xie et al. 2010). $\mathrm{Li}_{7} \mathrm{La}_{3} \mathrm{Zr}_{2} \mathrm{O}_{12}$ (LLZ) was calcined to obtained garnetlike structure pellet that in a symmetric $\mathrm{Li}$ cell showed interfaced stability, reversible plating and de-plating with no reaction. However, $\mathrm{Li} / \mathrm{LLZ} / \mathrm{LiCoO}_{2}$ cell that was successfully cycled showed irreversible behavior between LLZ and $\mathrm{LiCoO}_{2}$ (Kotobuki et al. 2010b).

To improve ceramic electrolyte-electrode compatibility and still maintain good overall cell capacity, nanoscale intermediary films were used to prevent interfacial reactions. $\mathrm{LiCoO}_{2}$ cathodes were spray coated with $\mathrm{Li}_{4} \mathrm{Ti}_{5} \mathrm{O}_{12}$ to form a protective layer between the cathode and sulfide electrolyte thio-LiSICON, which prevented formation of a highly resistive space-charge layer (Ohta et al. 2006). In a more recent work, $\mathrm{Li}_{2} \mathrm{O}-\mathrm{SiO}_{2}$, a coating without a transition metal oxide, was shown to be effective in protecting $\mathrm{LiCoO}_{2}$ for use with sulfide electrolyte $\mathrm{Li}_{2} \mathrm{~S}-\mathrm{P}_{2} \mathrm{~S}_{5}$ (Sakuda et al. 2008).

Ceramic electrolytes as a whole also have drawbacks that limit their implementation. They are brittle and can require more expensive processing conditions such as hightemperature sintering $\left(>1,300^{\circ} \mathrm{C}\right)$ and deposition by sputtering (Mei et al. 2009). The brittleness of the ceramic electrolyte can result in cracking, as the electrolyte is unable to accommodate volume changes in the electrodes due to lithium insertion/de-insertion. To mitigate this concern, a recent study investigated pairing the ceramic electrolyte against a polymer electrolyte that allowed for volume expansion (Tenhaeff et al. 2011). The brittleness of the ceramic electrolyte also limits the cell configurations it may be used in: traditionally, ceramic electrolytes were considered only for flat, thin film batteries. The growing field of micro electromechanical systems (MEMS) being developed requires a power source with maximum energy density and a minimized footprint; to meet this end, 3D battery configurations are being explored.

Ceramic electrolytes are ideal candidates for MEMS applications because not only are they immobile solids, but they are also thermally stable at the high temperatures present locally in microcircuits. Recently, conformal LiPON films were successfully deposited by magnetron sputtering in $\mathrm{N}_{2}$ gas at $2.6 \mathrm{~Pa}$ on both off-axis planar substrates and 3D substrates with 10-100 $\mu \mathrm{m}$ features (Xu et al. 2010). While the deposition rate decreases for offaxis areas and the film composition varies, the electrolyte still provides a nearly uniform $\mathrm{Li}^{+}$ionic conductivity of $2 \pm 1 \times 10^{-6} \mathrm{~S} / \mathrm{cm}$ throughout. In another study, 3D batteries were fabricated using a honeycomb, LLT electrolyte filled with oxide cathode particles and sol gel precursors (Kotobuki et al. 2010c). Good electrolyte-electrode contact was formed via this method, and a battery utilizing an $\mathrm{LiMnO}_{4}$ cathode displayed low interfacial impedance. The batteries were successfully cycled, but suffered from very poor discharge capacities, attributed to the large size of the electrolyte honeycomb pores $(180 \mu \mathrm{m})$.

\section{Polymer electrolytes}

Polymers have long been recognized as promising electrolyte candidates. Unlike brittle ceramic electrolytes, polymer-based electrolytes have the advantage of being lightweight and flexible, allowing for coiled cell configurations. Polymer electrolytes, unlike some ceramics, are unreactive with common oxide electrodes; they also perform better than liquid electrolytes in conjunction with sulfur cathodes and display wide electrochemical stability windows. The main drawback of polymer electrolytes is their low ionic conductivity, especially at room temperature.

In 1973, polyethylene oxide (PEO) was found to be conductive when complexed with an alkali metal salt (Fenton et al. 1973). In 1979, the first battery using a solid polymer electrolyte (SPE), PEO complexed with a lithium salt, was produced (Armand et al. 1979). Remarkably, the majority of work in this field is still dedicated to PEO due to its relatively high ionic conductivity when compared with other polymers. PEO-based electrolytes have traditionally been plagued with poor room-temperature conductivity due to crystallization of the matrix, so efforts have been made to extend amorphicity into the roomtemperature range. Large organic salts such as LiTFSI aid in this regard, as the anions act as a plasticizer, allowing the polymer chains to move more freely.

While improvements in conductivity are desirable, studies have shown that among electrolytes with similar lithium ion conductivity, those with high total ionic conductivity and low lithium transference numbers exhibit poorer electrochemical properties (Doyle et al. 1994). In addition, theoretical predictions by Rosso et al. (2001) suggest that the onset time for dendritic lithium growth, and subsequent short circuit time, has an inversely squared dependence on the anion transference number. Thus it is desirable to make single ion polymer conductors, or ionomers-polymer backbones with tethered anions that associate with free $\mathrm{Li}^{+}$. Colby et al. have shown that ions 
in these environments tend to aggregate into pairs, trimers or quadapoles, with few free lithium ions (Klein et al. 2006; Fragiadakis et al. 2008, 2009; Wang et al. 2010b). Therefore, conduction is governed by the trimer, which moves by segmental motion of the backbone, dissociating and reforming as it travels. This mechanism leads to impractically low conductivities in these systems, though lithium transference is unity. Recently, mixed polymer systems of PEO and poly(lithium acrylate) salts were shown to have improved conductivity $\left(10^{-6} \mathrm{~S} / \mathrm{cm}\right.$ at room temperature and $10^{-4} \mathrm{~S} / \mathrm{cm}$ at elevated temperatures) in the presence of the additive $\mathrm{BF}_{3} \mathrm{OEt}_{2}$, which coordinates with the tethered carboxylate anion and promotes ion-pair dissociation (Itoh et al. 2009). This study suggests that single ion-conducting conductors with high conductivity may be possible with improvements in anion coordinating additives.

Amorphous polymer electrolytes typically soften with improvements in ionic conductivity; this loss of mechanical integrity makes them less desirable for application in lithium metal-based batteries. Improvements in mechanical properties of solid-state polymer-based electrolytes have been demonstrated via cross-linked polymer, block co-polymer and small molecule polymer crystalline electrolytes, as well as polymer-ceramic composite and polymer-ceramic hybrid electrolytes, discussed in later sections.

Cross-linked polymer electrolyte films have been synthesized by a number of methods, including chemical cross-linking (Borghini et al. 1996; Matoba et al. 2002; Fogeling et al. 2010), photochemically cross-linking (Rupp et al. 2008), UV-cross-linking (Choi and Park 2009) and electron-beam cross-linking (Uchiyama et al. 2009). Solid cross-linked electrolytes based on PEO, without added solvent, generally exhibit ionic conductivities around $10^{-5} \mathrm{~S} / \mathrm{cm}$ at room temperature as the cross-linking inhibits chain crystallization, though it slows chain mobility. Cross-linking also increases the tensile strength of the films to the MPa range.

The majority of studies in the block copolymer electrolyte field has centered on materials with continuous, majority PEO blocks and minority blocks of a stiffer, typically non-conducting polymer to enhance mechanical properties. We will highlight two recent works. Ghosh et al. (2010 and Ghosh and Kofinas (2008) synthesized a PEO-b(PMMA-ran-PMMALi) diblock copolymer with a minority random copolymer block of methyl methacrylate (MMA) and lithium salt of methacrylic acid (MMALi) to provide an additional lithium source. When doped with $\mathrm{LiBC}_{4} \mathrm{O}_{8}$ (LiBOB), the copolymer electrolyte is a transparent, flexible film with an ionic conductivity of $1 \times 10^{-5} \mathrm{~S} / \mathrm{cm}$, lithium transference of 0.9 and electrochemical stability above $5 \mathrm{~V}$ at room temperature. Niitani et al. (2009) reported a polystyrene (PS)-block-polyethylene glycol methyl ethyl

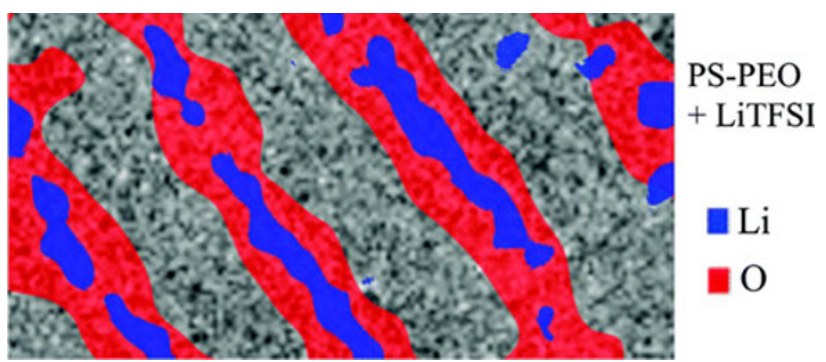

Fig. 7 Distribution of lithium in a PS-PEO block copolymer electrolyte doped with LiTFSI as determined by energy-filtered transmission electron microscopy (reprinted with permission from Gomez et al. 2009, Copyright (2009) American Chemical Society)

methacrylate (PPEGMA) $)_{2}$ star-shaped copolymer with a PS core and PPEGMA arms. When doped with LiBETI, the star copolymer electrolyte is a flexible film with a total ionic conductivity in the order of $10^{-4} \mathrm{~S} / \mathrm{cm}$ at room temperature. The notable enhanced total ionic conductivity of this electrolyte may be attributed to the geometric configuration of the block copolymer, where many short ethylene oxide chains are employed instead of one long chain, which inhibits crystallization of the conducting phase.

Decoupling of mechanical and conduction properties in a block copolymer electrolyte has been demonstrated by Singh et al. (2007) and Gomez et al. (2009) using a material with a continuous non-conducting phase (Fig. 7). The PS-block-PEO lamellar electrolytes, doped with LiTFSI, manifested ionic conductivities in the range $10^{-4}$ $10^{-5} \mathrm{~S} / \mathrm{cm}$ from 90 to $120^{\circ} \mathrm{C}$ and dynamic storage moduli of $10^{7}-10^{8} \mathrm{~Pa}$. The lamellar block copolymer electrolyte exhibited significant improvement in mechanical properties with little change in conductivity, thereby demonstrating that independent control of these properties is possible. Energy-filtered TEM showed that ions were accumulating, increasingly localized, at the center of the PEO lamellae as the chain molecular weight increased. Stress calculations indicate that local stress interferes with the ability of the PEO near the phase boundaries to interact with the salt, thus decreasing ion concentration in wall regions that have lower mobility. Overall, the properties of the lamellar block copolymer electrolyte are quite attractive at elevated temperatures $\left(\sim 100^{\circ} \mathrm{C}\right)$; improvement in conductivity at lower temperatures appears necessary for use of the system in a room-temperature secondary battery.

Decoupling of mechanical and conduction properties in polymers has also been demonstrated by a relatively new class of materials, crystalline polymer-salt complexes or small molecule electrolytes (Gadjourova et al. 2001; Christie et al. 2005; Bruce 2008; Bruce et al. 2008). These complexes of short PEO chains (glymes) and lithium salt form crystals with varying structures depending on the $\mathrm{EO} /$ $\mathrm{Li}^{+}$ratio and glyme length. In most cases, the glyme chain 
forms a helix around the lithium ions, and anions are free outside of the helix. The lithium ions are then able to conduct through the helix tunnel and along the glyme backbone. Increasing order, and therefore decreasing defects between tunnels, improves the ionic conductivity. Dopants of lithium salts with a different ion (i.e., addition of a small amount of LiTFSI to an $\mathrm{LiAsF}_{6}$-doped electrolyte) have been shown to improve conductivity, as have increasing the number of chain ends per crystallite and having chains with $-\mathrm{OC}_{2} \mathrm{H}_{5}$ ends. The ionic conductivity of crystalline electrolytes is still low, $10^{-8}$ to $10^{-6} \mathrm{~S} / \mathrm{cm}$ at room temperature, but this field is relatively new. Like all polymer electrolytes, they are easily processable-an advantage over their ceramic electrolyte counterparts.

Polymer-ceramic composite electrolytes

The addition of ceramic nanoparticles, such as $\mathrm{TiO}_{2}($ Croce et al. 1998, 1999; Jeon et al. 2006), $\mathrm{SiO}_{2}$ (Raghaven et al. 2008; Capiglia et al. 1999), $\mathrm{Al}_{2} \mathrm{O}_{3}$, (Bruce 2008; Krawiec et al. 1995; Jayathilaka et al. 2002) $\mathrm{Fe}_{3} \mathrm{O}_{4}$ (Reddy et al. 2006) and $\mathrm{S}-\mathrm{ZrO}_{2}$ (Croce et al. 2006; Panero et al. 2007) to polymer electrolytes has been shown to improve ionic conductivity, and mechanical and electrochemical properties of the polymer electrolyte. The increase in ionic conductivity in composite electrolytes (CPEs) with inert fillers has been attributed to the nanoparticles acting as solid plasticizers, disturbing polymer crystallization. Comparative studies of nanofillers with varying chemistries and surface functionalized nanofillers reveal that the electrostatic environment near the particle surface can promote conduction of one species over another. It is understood that Lewis acid-base surface groups interact with ions and PEO segments to create additional conduction pathways along the particle surfaces for lithium cations and/or interfere with anion transport.

Inadequate movement of polymer chains next to an electrode surface leads to a decline in salt transport and thus an increase in a salt concentration gradient (Kerr et al. 2004). The addition of ceramic additives increases polymer amorphicity and chain mobility. Ceramic fillers also can scavenge impurities from the electrolyte, which may have undesirable reactions with the electrode (Mazor et al. 2008). These combined effects reduce the interfacial resistance at the lithium electrode (Bruce 2008; Jeon et al. 2006). Reduction in the SEI improves the interface stability and reduces dendrite formation on lithium metal anodes. CPEs also have enhanced mechanical properties, with an increase in the Young's modulus and yield strength. Still, even with the use of additives such as calix(6)pyrrole (Jayathilaka et al. 2002; Croce et al. 2006), solid-state composite polymer systems based on high molecular weight PEO suffer from low ionic conductivity at room temperature and below, which limits their practical application.

Polymer-ceramic hybrid electrolytes

Polymer-ceramic hybrid electrolytes are studied for their potential to improve mechanical properties and prevent crystallization of polymer-based electrolytes. Miscibility between the organic and inorganic constituents of these materials is a concern that can be alleviated by appropriate chemistry. The majority of these hybrid materials have molecular-scale inorganic regions cross-linked by an organic component. They are often synthesized by a sol-gel technique, polycondensation reactions of alkoxysilanes and end-functionalized homopolymers or copolymers (Popall et al. 1998; Kao et al. 2006; Jeyapandian et al. 2010). Hybrid materials of similar form but varying chemistry were recently demonstrated by the reaction of polyethylene glycol with organometallic precursor methylaluminoxane, an oxyaluminum cluster that contains up to 12 active reaction sites (Piszcz et al. 2010). A deviation from this form was reported by Kao and Chen (2004) who synthesized a mesoscopically ordered electrolyte with hexagonal arrays of inorganic cylinders by co-condensation of glydicyloxypropyl) trimethoxysilane (GLYMO) and tetraethoxysilane (TEOS) and self-assembly of PEO-PPO-PEO triblock copolymer. Ionic conductivities in the range of $10^{-6}-10^{-4}$ $\mathrm{S} / \mathrm{cm}$ at room temperature are typical of these hybrids; the framework is typically successful in preventing polymer crystallization above room temperature. Notably, all of these studies fail to characterize the mechanical properties of the electrolyte and it is not clear how their strength compares to that of pure polymer and composite polymer electrolytes.

Recently, we reported on the synthesis of organicinorganic hybrids created by dense functionalization of nanoscale ceramic particles with short polymer chains (Nugent et al. 2010). Physical properties of these materials are facilely tuned by changing the polymer chain (corona) length, grafting density, as well as the particle size and inorganic content of the hybrids. The systems exist as jammed, self-suspended suspensions of nanoparticles (Nugent et al. 2010; Agarwal et al. 2010, 2011), which manifest a yield stress and, depending on the corona molecular weight, exhibit room-temperature ionic conductivities from $10^{-3}$ to $10^{-6} \mathrm{~S} / \mathrm{cm}$. Hybrids based on corona chains with terminal, reactive functional groups allow the nanoparticle cores to be cross-linked to yield homogeneous organic-inorganic hybrid films with tensile moduli exceeding $0.1 \mathrm{GPa}$ at room temperature (Agarwal et al. 2010, 2011). Doping these films with a $1 \mathrm{M}$ solution of LiTFSI in TEGDME produces a tenfold reduction in the modulus to $\sim 10 \mathrm{MPa}$ (Fig. 8) and room-temperature ionic conductivities of $2 \times 10^{-5} \mathrm{~S} / \mathrm{cm}$. 
Fig. 8 Cross-linked, nanoporous $\mathrm{SiO}_{2}$-PEG film. a Photograph and $\mathbf{b}$ schematic of PEG hybrid's highlighting cross-linked chains; c dynamic elastic modulus; and $\mathbf{d}$ ionic conductivity of cross-linked hybrid film as a function of temperature, after swelling with $1 \mathrm{M}$ LiTFSI in TEGDME

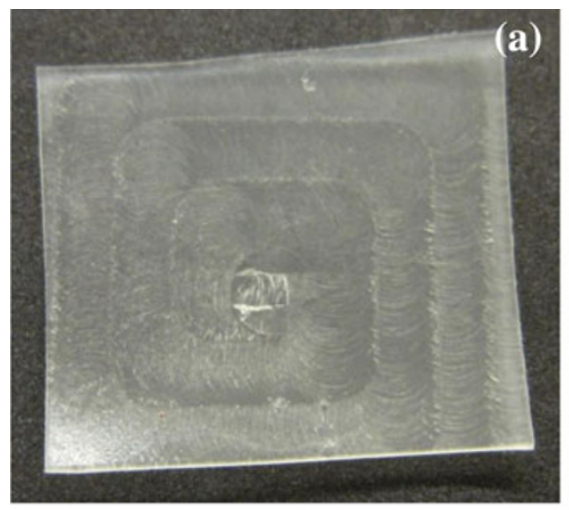

(b)
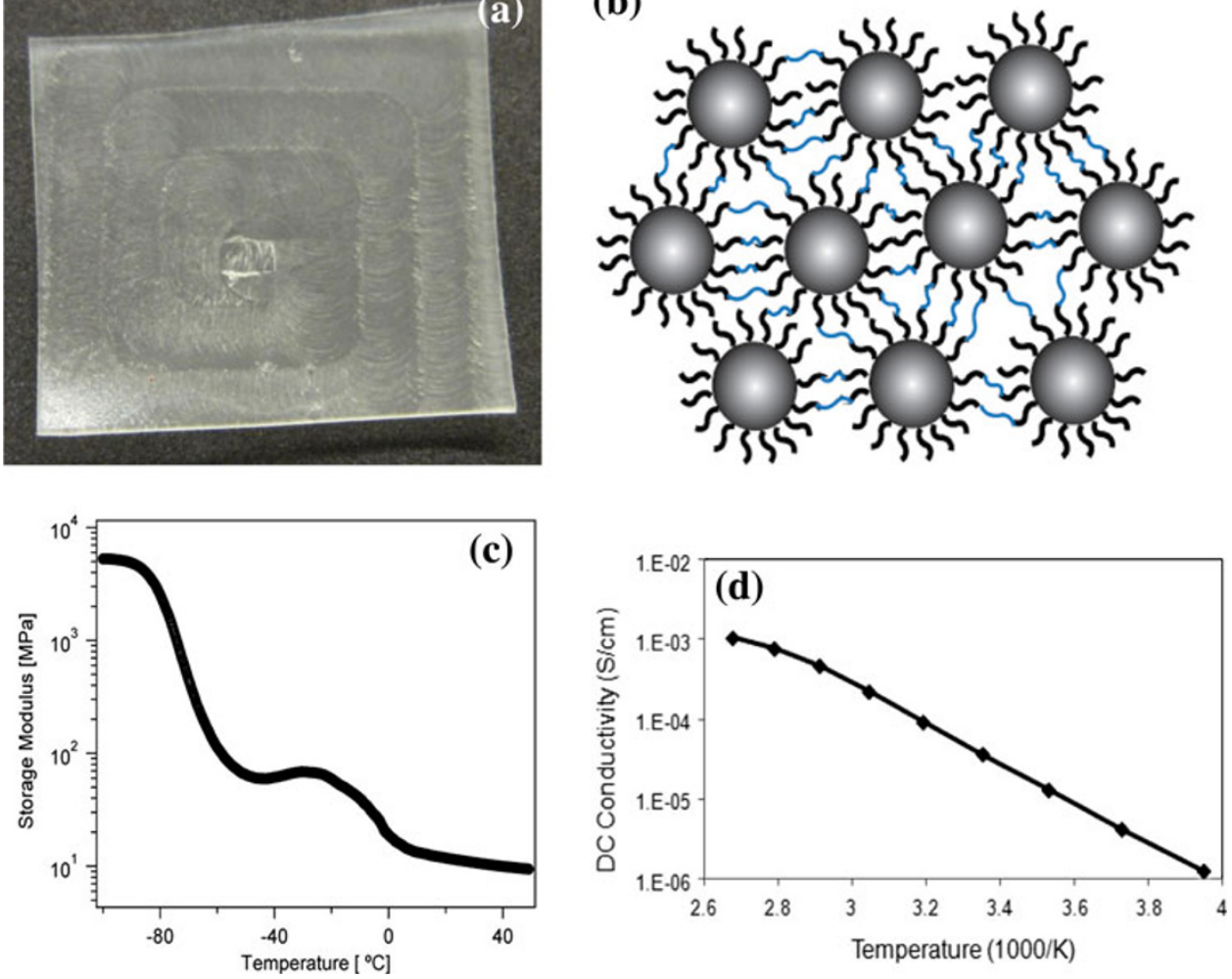

\section{Mixed phase electrolytes}

Mixed phase electrolytes, containing both solid and liquid components, offer a compromise in material properties, whereas the liquid aids in conduction and the solid enhances mechanical properties. The majority of work in this field has previously been devoted to gel polymer electrolytes and soggy sand electrolytes.

Polymer-liquid electrolytes

Gel polymer electrolytes comprise a polymer matrix swollen with a liquid electrolyte, with or without a ceramic particle additive. The gel polymer is a free-standing film that eliminates the problem of leakage as with a traditional liquid electrolyte and thus the need for a separator, but still has nearly the same ionic conductivity and electrochemical properties of the imbibing fluid. The polymer matrix may be cross-linked or uncross-linked.

In the 1990s, Bellcore commercially produced the first plastic Li ion battery. It utilized a poly(vinylidene fluoride)-hexafluoropropylene (PVdF-HFP) matrix with an EC-DMC-LiPF 6 liquid electrolyte and $\mathrm{SiO}_{2}$ filler in an $\mathrm{LiMn}_{2} \mathrm{O}_{4} / \mathrm{C}$ cell (Tarascon et al. 1996). PVdF-HFP is a copolymer with good mechanical integrity, chemical stability and miscibility with carbonate-based electrolytes, unlike PEO. Still, the Bellcore electrolyte suffers from the other problems associated with aprotic liquid electrolytes: low thermal stability, low cathodic stability, volatility, flammability and insufficient moduli to prevent dendritic lithium growth. Ionic liquid-based gel polymer electrolytes are now widely studied as a possible solution to some of these issues (Rupp et al. 2008; Fuller et al. 1998; Nakagawa et al. 2003; Cheng et al. 2007; Liao et al. 2010); PEO-based gel polymer electrolytes have also been explored, by swelling a high molecular weight PEO matrix with PEG oligomers (Borghini et al. 1996).

Ceramic-liquid electrolytes

"Soggy sand" electrolytes are created by doping a liquid electrolyte with ceramic nanoparticles (Bhattacharyya et al. 2004; Das and Bhattacharyya 2009, 2010; Walls et al. 2003). At a given particle volume fraction $\phi_{\text {onset }} \ll 0.01$, a percolating particle network forms in the system (Fig. 9) and the physical nature of the bulk material may become gel-like. This gel state, similar to that achieved in polymerliquid gel electrolytes, may render the separator in $\mathrm{Li}$ ion cells unnecessary. The onset percolation threshold $\Phi_{\text {onset }}$ is a function of the chemical moieties on the particle surface for a given particle size, and the network is formed by hydrogen bonding and/or Van der Waals interactions between surface groups.

Certain dopants, such as unmodified aerosol silica (Bhattacharyya et al. 2004), methyl-capped aerosol silica (Bhattacharyya et al. 2004) or Li-exchanged hectorite 
Fig. 9 Transmission electron micrographs showing the intrinsic morphology of nonfunctionalized and functionalized aerosil silica particles used in the preparation of soggy sand electrolytes: a as received; b methyl capped; c amine capped; and $\mathbf{d}$ octyl capped. (reprinted with permission from Das and Bhattacharyya (2009), Copyright (2009) American Chemical Society)
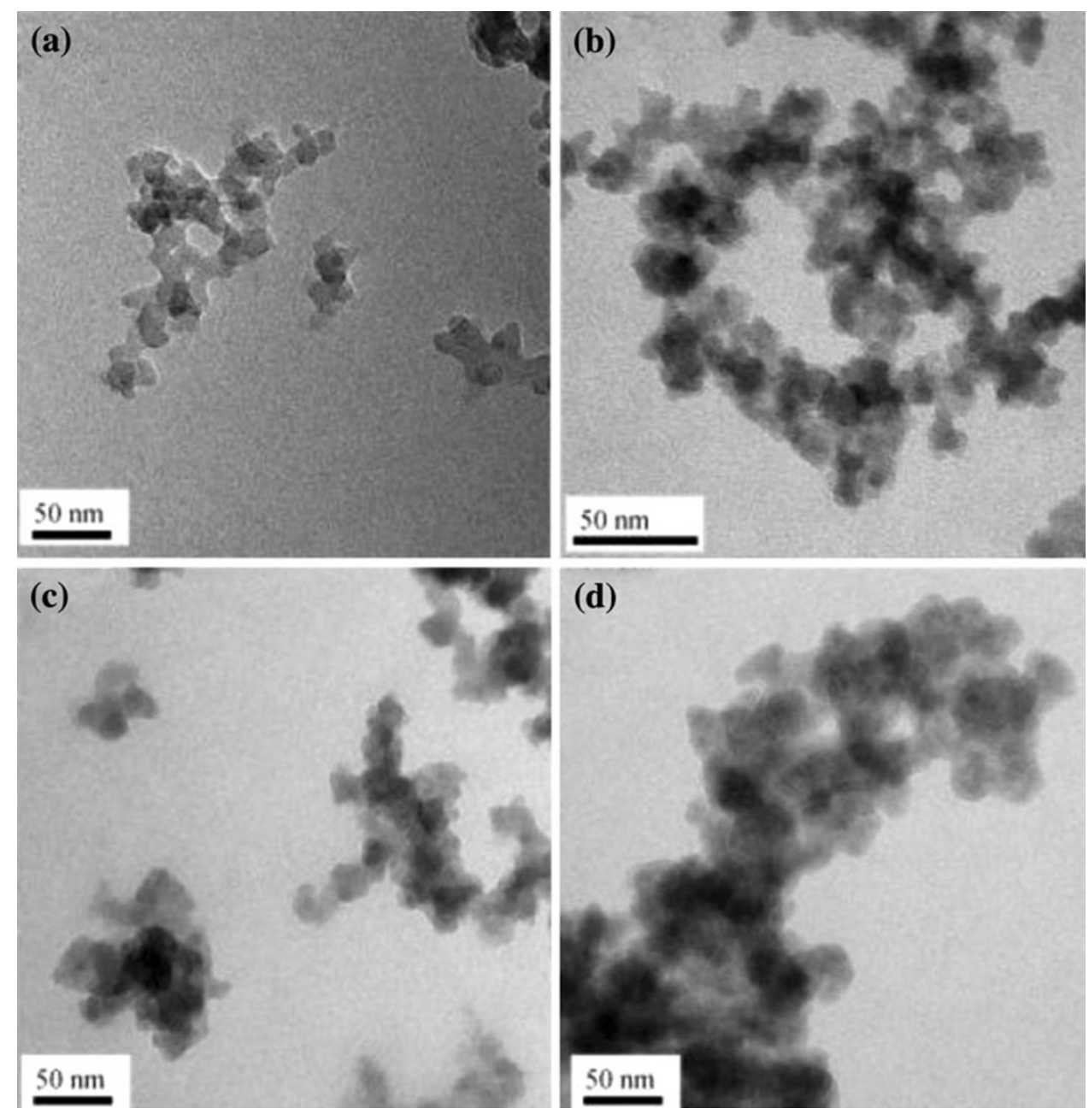

nanoclay (Das and Bhattacharyya 2010), may increase ionic conductivity of the electrolyte up to half an order of magnitude at low $\phi>\phi_{\text {onset }}$ by attracting the anion, thus breaking up an ion pair and freeing $\mathrm{Li}^{+}$for conduction. Beyond a threshold volume fraction $\phi_{\max }$, the ionic conductivity then declines due to blocking of the ionic conduction pathways. A soggy sand electrolyte of lithium perchlorate-ethylene glycol solution doped with unmodified aerosol silica at $\phi=0.07$ has a storage modulus $G^{\prime}=$ $5 \times 10^{-4} \mathrm{~Pa}$ and ionic conductivity of $7 \times 10^{-4} \mathrm{~S} / \mathrm{cm}$ at room temperature, a $30 \%$ increase in conductivity compared with the pure electrolyte solution (Bhattacharyya et al. 2004). However, a change in the liquid to lithium perchlorate-methoxy polyethylene glycol solution resulted in a gel with $G^{\prime}=1 \times 10^{-6} \mathrm{~Pa}$ and ionic conductivity of $1 \times 10^{-4} \mathrm{~S} / \mathrm{cm}$, withno improvement in conductivity over the undoped solution (Das and Bhattacharyya 2009). The effect of bonding structure and surface chemistry on conductivity in soggy sand electrolytes is still under investigation.
Ceramic-IL nanocomposites ILs have been investigated as electrolytes for dye-sensitized solar cells. Wang et al. (2004b) and Katakabe et al. (2007) have both noted improved properties by doping an IL electrolyte with silica.

Recently, Syzdek et al. (2009) reported on a liquid-inceramic composite, where the ceramic provides a continuous supporting phase and is soaked with a liquid electrolyte. The porous ceramic matrix was formed by a tape-casting method, uni-axial pressing and grain sintering of a slurry of $\gamma-\mathrm{Al}_{2} \mathrm{O}_{3}$ particles. Electrolytes were prepared by soaking the ceramic matrix in various $\mathrm{PEGDME} / \mathrm{LiClO}_{4}$ liquids. The electrochemical properties of the resulting electrolyte were found to depend on the liquid component and porosity of the support matrix.

\section{Nanoporous hybrid electrolytes}

Recently, we reported on a new class of mixed phase electrolytes, nanoporous hybrid electrolytes, of zirconiaimidazolium based ionic liquid hybrid $\left(\mathrm{ZrO}_{2}-\mathrm{IL}\right)$ doped 
Fig. $10 \mathrm{ZrO}_{2}$-IL hybrid electrolyte with a tethered imidazolium-based cation and free TFSI anion, doped with 1 M LiTFSI: a transmission electron micrograph of $\mathrm{ZrO}_{2}$-IL particles; b dynamic shear moduli as a function of shear strain at $50^{\circ} \mathrm{C}$; c schematic, where red indicates imidazolium cation, black $\mathrm{Li}^{+}$ and blue $\mathrm{TFSI}^{-}$; $\mathbf{d}$ ionic conductivity
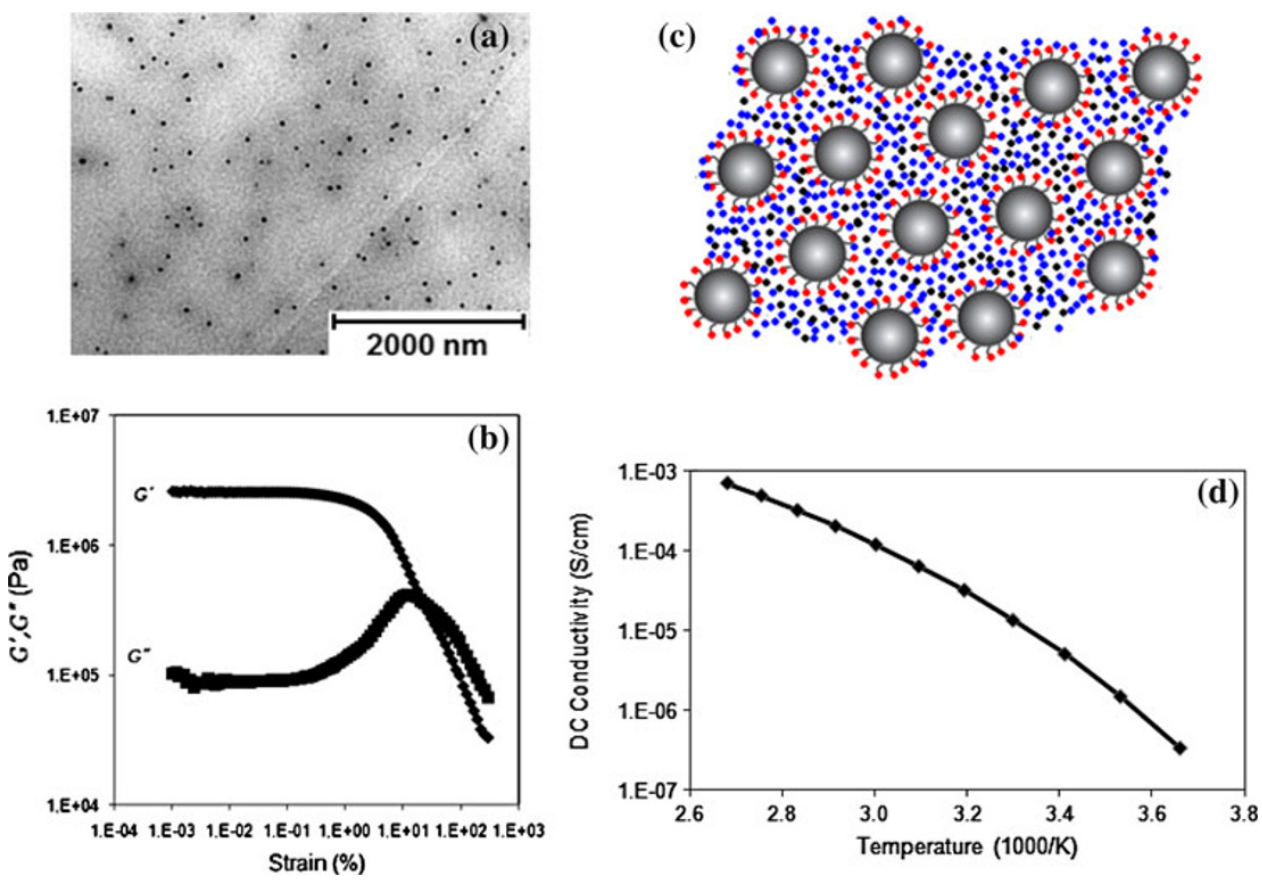

with LiTFSI (Fig. 10) (Moganty et al. 2010) and silicapolyethylene glycol $\left(\mathrm{SiO}_{2}-\mathrm{PEG}\right)$ hybrids suspended in PEGDME/LiTFSI (Fig. 11) (Schaefer et al. 2011). Like the solvent-free, cross-linked electrolytes introduced in "Polymer-ceramic hybrid electrolytes", both of these systems have uniformly dispersed, non-agglomerated ceramic nanocores surrounded by a percolating, organic ionic conduction pathway. This percolating conduction pathway allows for good ionic conductivities even at high particle loadings. $\mathrm{A} \mathrm{SiO}_{2}$-PEG suspension electrolyte with $\phi=0.38$ displays a storage modulus close to $1 \mathrm{MPa}$ and an ionic conductivity of $3.5 \times 10^{-4} \mathrm{~S} / \mathrm{cm}$ at $35^{\circ} \mathrm{C}$, as well as a practical conductivity of $1.0 \times 10^{-4} \mathrm{~S} / \mathrm{cm}$ at $10^{\circ} \mathrm{C}$. In comparison, the $\mathrm{ZrO}_{2}$-IL electrolyte displayed an ionic conductivity of $7 \times 10^{-4} \mathrm{~S} / \mathrm{cm}$ at $100^{\circ} \mathrm{C}$ and $2 \times 10^{-5} \mathrm{~S} / \mathrm{cm}$ at $25^{\circ} \mathrm{C}$ with a storage modulus of $5 \mathrm{MPa}$ at $150^{\circ} \mathrm{C}$. Significantly, the $\mathrm{ZrO}_{2}$-IL electrolyte has a lithium transference number $\mathrm{T}_{\mathrm{Li}+}=0.35 \pm 0.04$, seven times larger than the value for the pure IL electrolytes (0.05) (Hayamizu et al. 2004). This improvement in lithium transference is attributed to the tethering of the IL imidazolium cation, leaving $\mathrm{Li}^{+}$as the only mobile cation in the system. Both of these systems display wide electrochemical stability windows and stable interfacial impedances against lithium metal.

Unlike previously studied electrolytes, these nanoporous hybrids behave mechanically as soft glasses when $\phi>\phi^{*}$, the threshold value for particle jamming. At ceramic fractions above $\phi^{*}$ and at rest or under low strain $(\gamma)$, the electrolyte is jammed and behaves as a solid. When the applied strain exceeds the yield strain $\gamma_{y}$, the electrolyte flows as a liquid; this property is significant because it means that the electrolyte behaves as a solid in static conditions, such as inside a battery, yet can be facilely processed during normal cell assembly.

\section{Conclusions}

From aqueous liquid electrolytes for lithium-air cells to ionic liquid electrolytes that permit continuous, high-rate cycling of secondary batteries comprising metallic lithium anodes, we show that many of the key impediments to progress in developing next-generation batteries with high specific energies can be overcome with cleaver designs of the electrolyte. When these designs are coupled with cleverly engineered electrode configurations that control chemical interactions between the electrolyte and electrode (e.g., in Li/sulfur cells that employ encapsulation/physisorption strategies for limiting dissolution of redox products in the electrolyte) or by simple additives-based schemes for manipulating physical contact between the electrolyte and electrode (e.g., through sacrificial additives that spontaneously form a stabilizing SEI layer), we further show that rechargeable battery configurations can be facilely designed to maximize performance and cycling stability. Judging from the large number of degrees of freedom inherent in synthesizing organic-inorganic hybrid materials systems with explicit desired properties, and the recent upsurge in interest in synthesizing ionic liquids with tunable solvation and ion transport properties, while preserving their desirable thermal and electrochemical stability, we are optimistic that in a matter of few years commercially viable electrolytes will begin to appear that are suitable for safe deployment in the most energy-dense battery configurations of all, those based on the metal-air cell. 

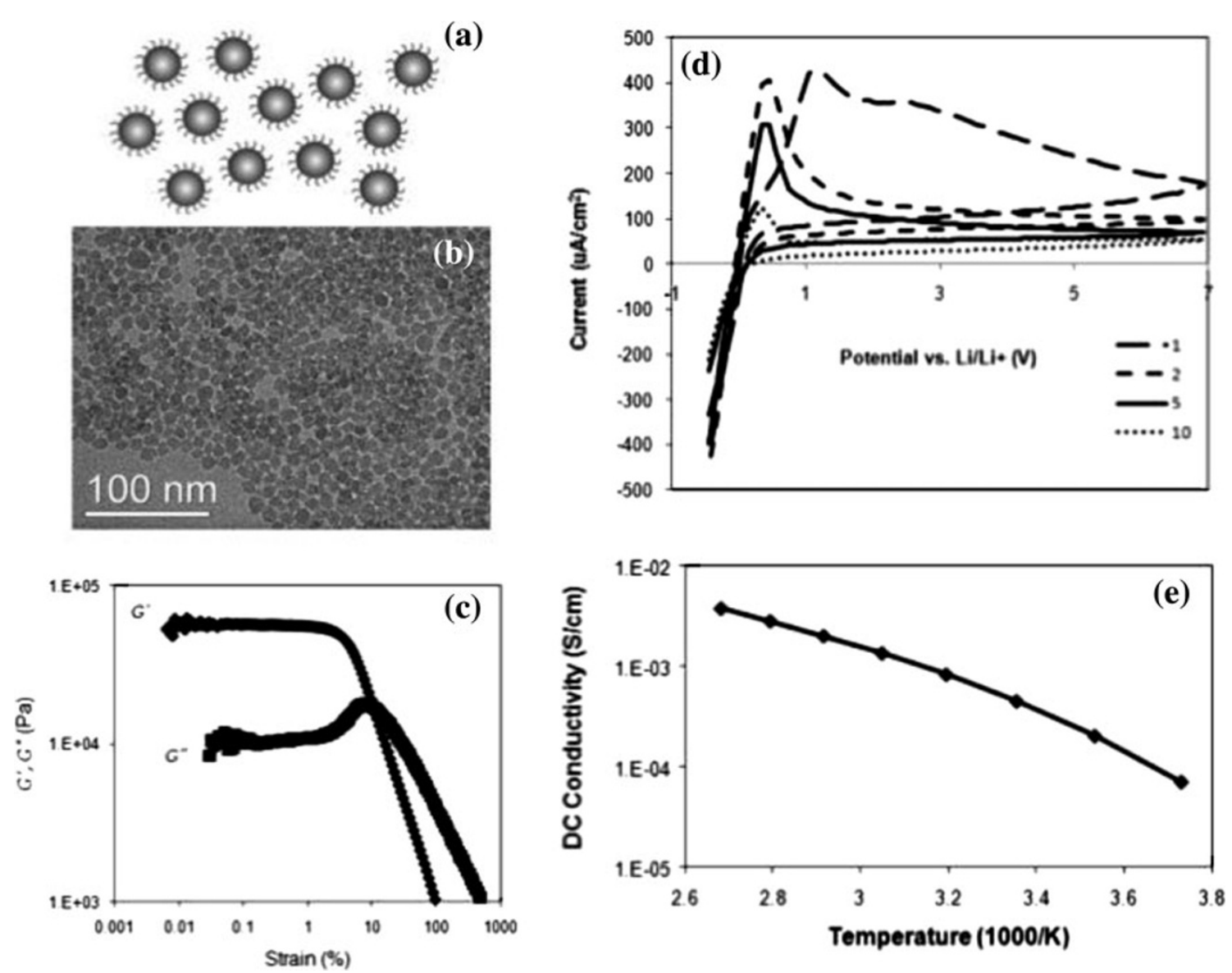

Fig. $11 \mathrm{SiO}_{2}$-PEG hybrid suspended in PEGDME and doped with $1 \mathrm{M}$ LiTFSI in the organic phase, $\phi=0.3$ : a schematic of hybrid suspensions; b transmission electron micrograph of $\mathrm{SiO}_{2}-\mathrm{PEG} /$ PEGDME; c dynamic shear moduli as a function of strain at $35^{\circ} \mathrm{C}$;

Acknowledgments Study on the synthesis, and mechanical and electrochemical characterization of nanoscale organic hybrid materials (NOHMs) was supported in part by Award No. KUS-C1-018-02, made by King Abdullah University of Science and Technology (KAUST) and by the National Science Foundation, Award No. DMR1006323. Work on C@S hybrid lithium battery cathodes and the search for electrolytes for these systems was supported as part of the Energy Materials Center at Cornell, an Energy Frontier Research Center funded by the U.S. Department of Energy, Office of Basic Energy Sciences under Award Number DE-SC0001086. JLS also gratefully acknowledges support from the Materials for a Sustainable Future IGERT program, NSF grant \# DGE-0903653.

Open Access This article is distributed under the terms of the Creative Commons Attribution License which permits any use, distribution and reproduction in any medium, provided the original author(s) and source are credited.

\section{References}

Agarwal P, Qi H, Archer LA (2010) The ages in a self-suspended nanoparticle liquid. Nano Lett 10(1):111-115

Agarwal P, Chopra M, Archer LA (2011) Nanoparticle netpoints for shape-memory polymers. Angew Chem Int Ed 50(37):8670-8673

d cyclic voltammetry of a $\mathrm{Li} / \mathrm{electrolyte} / \mathrm{Li}$ cell at a scan rate of $1 \mathrm{mV} / \mathrm{s}$ for ten cycles from -0.5 to $7.0 \mathrm{~V}$ versus $\mathrm{Li} / \mathrm{Li}^{+}$; e ionic conductivity of $\mathrm{SiO}_{2}$-PEG/PEGDME suspension with $\phi=0.3$

Appetecchi GB, Montanino M, Zane D, Carewska M, Alessandrini F, Passerini S (2009) Effect of the alkyl group on the synthesis and the electrochemical properties of N-alkyl-N-methyl-pyrrolidiumiun bis(trifluoromethanesulfonyl)imide ionic liquids. Electrochim Acta 54(4):1325-1332

Arai J (2003) Nonflammable methyl nonafluorobutyl ether for electrolyte used in lithium secondary batteries. J Electrochem Soc 150(2):A219-A228

Armand MB, Chabagno JM, Duclot MJ (1979) In: Fast ion transport in solids: electrodes and electrolytes. Vashista P, Mundy JN, Shenoy GK (eds) North-Holland, New York, pp 131

Aurbach D, Markovsky B, Salitra G, Markevich E, Talyossef Y, Koltypin M, Nazar L, Ellis B, Kovacheva D (2007) Review on electrode-electrolyte solution interactions, related to cathode materials for Li-ion batteries. J. Power Sources 165(2):491-499

Balakrishnan PG, Ramesh R, Kumar TP (2006) Safety mechanisms in lithium-ion batteries. J Power Sources 155(2):401-414

Bayley PM, Lane GH, Rocher NM, Clare BR, Best AS, MacFarlane DF, Forsyth M (2009) Transport properties of ionic liquid electrolytes with organic diluents. Phys Chem Chem Phys 11(33):7202-7208

Bennemann H, Brouers F, Quitmann D (1982) Ionic liquids, molten salts and polyelectrolytes. In: Proceedings of international conference on molten salts, Springer, New York

Bhatt AI, Best AS, Huang J, Hollenkamp AF (2010) Application of the N-propyl-N-methyl-pyrrolodinium bis(fluorosulfonyl)imide

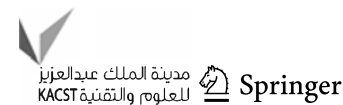


RTIL containing lithium bis(fluorosulonyl)imide in ionic liquid based lithium batteries. J Electrochem Soc 157(1):A66-A74

Bhattacharyya A, Dolle M, Maier J (2004) Improved battery electrolytes by heterogeneous doping of nonaqueous $\mathrm{Li}$-salt solutions. Electrochem Solid State Lett 7(11):A432-A434

Borgel V, Markevicha E, Aurbach D, Semrau G, Schmidt M (2009) On the application of ionic liquids for rechargeable Li batteries: High voltage systems. J Power Sources 189(1):331-336

Borghini MC, Mastragostino M, Zanelli A (1996) Reliability of lithium batteries with crosslinked polymer electrolytes. Electrochim Acta 41(15):2369-2373

Bruce PG (2008) Energy storage beyond the horizon: rechargeable lithium batteries. Solid State Ionics 179(21-26):752-760

Bruce PG, Scrosati B, Tarascon J-M (2008) Nanomaterials for rechargeable lithium batteries. Angew Chem Inter Ed 47(16):2930-2946

Capiglia C, Mustarelli P, Quartarone E, Tomasi C, Magistris A (1999) Effects of nanoscale $\mathrm{SiO}_{2}$ on the thermal and transport properties of solvent-free, poly(ethylene oxide) (PEO)-based polymer electrolytes. Solid State Ionics 118(1-2):73-79

Chang DR, Lee SH, Kim SW, Kim HT (2002) Binary electrolyte based on tetra(ethylene glycol) dimethyl ether and 1,3-dioxolane for lithium-sulfur battery. J Power Sources 112(2):452-460

Chen R, Wu F, Li L, Guan Y, Qiu X, Chen S, Li Y, Wu S (2007) Butylene sulfite as a film-forming additive to propylene carbonate-based electrolytes for lithium ion batteries. J Power Sources 172(1):395-403

Cheng H, Zhu C, Huang B, Lu M, Yang Y (2007) Synthesis and electrochemical characterization of PEO-based polymer electrolytes with room temperature ionic liquids. Electrochim Acta 52(19):5789-5794

Cheon SE, Ko KS, Cho JH, Kim SW, Chin EY, Kim HT (2003a) Rechargeable lithium sulfur battery-I. Structural change of sulfur cathode during discharge and charge. J Electrochem Soc 150(6):A796-A799

Cheon SE, Ko KS, Cho JH, Kim SW, Chin EY, Kim HT (2003b) Rechargeable lithium sulfur battery-II. Rate capability and cycle characteristics. J Electrochem Soc 150(6):A800-A805

Choi N-S, Park J-K (2009) A comparative study of coordination between host polymer and $\mathrm{Li}(+)$ ions in UV-cured gel polymer electrolytes. Solid State Ionics 180(20-22):1204-1208

Choi J-W, Kim J-K, Cheruvally G, Ahn J-H, Ahn H-J, Kim K-W (2007) Rechargeable lithium/sulfur battery with suitable mixed liquid electrolytes. Electrochim Acta 52(5):2075-2082

Choi J-W, Cheruvally G, Kim D-S, Ahn J-H, Kim K-W, Ahn H-J (2008) Rechargeable lithium/sulfur battery with liquid electrolytes containing toluene as additive. J Power Sources 183(1):441-445

Christie AM, Lilley SJ, Staunton E, Andreev YJ, Bruce PG (2005) Increasing the conductivity of crystalline polymer electrolytes. Nature 433(7021):50-53

Croce F, Appetecchi GB, Persi L, Scrosati B (1998) Nanocomposite polymer electrolytes for lithium batteries. Nature 394(6692): 456-458

Croce F, Curini R, Martinelli A, Persi L, Ronci F, Scrosati B, Caminiti R (1999) Physical and chemical properties of nanocomposite polymer electrolytes. J Phys Chem B 103(48):10632-10638

Croce F, Sacchetti S, Scrosati B (2006) Advanced, high-performance composite polymer electrolytes for lithium batteries. J Power Sources 161(1):560-564

Das S, Bhattacharyya A (2009) Oxide particle surface chemistry and ion transport in "soggy sand" electrolytes. J Phys Chem C 113(16):6699-6705

Das S, Bhattacharyya A (2010) Influence of oxide particle network morphology on ion solvation and transport in "soggy sand" electrolytes. J Phys Chem B 114(20):6830-6835
Davis JH (2004) Task-specific ionic liquids. Chem Lett 33(9): 1072-1077

Doyle M, Fuller TF, Newman J (1994) The importance of the lithium ion transference number in lithium polymer cells. Electrochim Acta 39(13):2073-2081

Egashira M, Okada S, Yamaki J, Dri DA, Bonadies F, Scrosati B (2004) The preparation of quaternary ammonium-based ionic liquid containing a cyano group and its properties in a lithium battery electrolyte. J Power Sources 138(1-2):240-244

El Ouatani L, Dedryvère R, Siret C, Biensan P, Reynaud S, Iratçabal P, Gonbeau D (2009) The effect of vinylene carbonate additive on surface film formation on both electrodes in Li-ion batteries. J Electrochem Soc 156(2):A103-A113

Fei S-T, Allcock HR (2010) Methoxyethoxyethoxyphosphazenes as ionic conductive fire retardant additives for lithium battery systems. J Power Sources 195(7):2082-2088

Fenton DE, Parker JM, Wright PV (1973) Complexes of alkali-metal ions with poly(ethylene oxide). Polymer 14(11):589

Fergus JW (2010) Ceramic and polymeric solid electrolytes for lithium-ion batteries. J Power Sources 195(15):4554-4569

Fogeling J, Kunze M, Schonhoff M, Stolwijk NA (2010) Foreign-ion and self-ion diffusion in a crosslinked salt-in-polyether electrolyte. Phys Chem Chem Phys 12(26):7148-7161

Fragiadakis D, Dou S, Colby RH, Runt J (2008) Molecular mobility, ion mobility, and mobile ion concentration in poly(ethylene oxide)-based polyurethane ionomers. Macromolecules 41(15): 5723-5728

Fragiadakis D, Dou S, Colby RH, Runt J (2009) Molecular mobility and $\mathrm{Li}(+)$ conduction in polyester copolymer ionomers based on poly(ethylene oxide). J Chem Phys 130(6):064907

Fuller J, Breda AC, Carlin RT (1998) Ionic liquid-polymer gel electrolytes from hydrophilic and hydrophobic ionic liquids. J Electroanal Chem 459(1):29-34

Gadjourova Z, Andreev YG, Tunstall DP, Bruce PG (2001) Ionic conductivity in crystalline polymer electrolytes. Nature 412(6846): 520-523

Ghosh A, Kofinas P (2008) Nanostructured block copolymer dry electrolyte. J Electrochem Soc 155(6):A428-A431

Ghosh A, Wang C, Kofinas P (2010) Block copolymer solid battery electrolyte with high Li-ion transference number. J Electrochem Soc 157(7):A846-A849

Girishkumar G, McCloskey B, Luntz AC, Swanson S, Wicke W (2010) Lithium-air battery: promise and challenges. J Phys Chem Lett 1(14):2193-2203

Gomez ED, Panday A, Feng EH, Chen V, Stone GM, Minor A, Kisielowshi C, Downing KH, Borodin O, Smith GD, Balsara NP (2009) Effect of ion distribution on conductivity of block copolymer electrolytes. Nano Lett 9(3):1212-1216

Goodenough JB, Kim J (2010) Challenges for rechargeable $\mathrm{Li}$ batteries. Chem Mater 22(3):587-603

Hamlen R, Au G, Brundage M, Hendrickson M, Plichta E, Slane S, Barbarello J (2001) US Army portable power programs. J Power Sources 97-98(SI):22-24

Hayamizu K, Aihara Y, Nakagawa H, Nukuda T, Price WS (2004) Ionic conduction and ion diffusion in binary room-temperature ionic liquids composed of [emim][BF4] and LiBF4. J Phys Chem B 108(50):19527-19532

Herbert EG, Tenhaeff WE, Dudney NJ, Pharr GM (2011) Mechanical characterization of LiPON films using nanoindentation. Thin Solid Films 520(1):413-418

Howlett PC, MacFarlane DR, Hollenkamp AF (2004) High lithium metal cycling efficiency in a room-temperature ionic liquid. Electrochem Solid State Lett 7(5):A97-A101

Howlett PC, Brack N, Hollenkamp AF, Forsyth M, MacFarlane DR (2006) Characterization of the lithium surface in N-methyl-Nalkylpyrrolidinium bis(trifluoromethanesulfonyl)amide room- 
temperature ionic liquids electrolytes. $\mathrm{J}$ Electrochem Soc 153(3):A595-A606

Hussey CL (1983) Ionic liquids. Advances in Molten Salt Chemistry, vol 5, p 185

Hyung YE, Vissers DR, Amine K (2003) Flame-retardant additives for lithium-ion batteries. J Power Sources 119(SI):383-387

Itoh T, Yoshikawa M, Uno T, Kubo M (2009) Solid polymer electrolytes based on poly(lithium carboxylate) salts. Ionics 15(1):27-33

Jayaprakash N, Shen J, Moganty SS, Corona A, Archer LA (2011) Porous hollow carbon@sulfur composites for high-power lithium-sulfur batteries. Angew Chem Int Ed 50(26):5904-5908

Jayathilaka PARD, Dissanayake MAKL, Albinsson I, Mellander B-E (2002) Effect of nano-porous $\mathrm{Al}_{2} \mathrm{O}_{3}$ on thermal, dielectric and transport properties of the (PEO)(9) LiTFSI polymer electrolyte system. Electrochim Acta 47(20):3257-3268

Jeon J-D, Kim M-J, Kwak S-Y (2006) Effects of addition of $\mathrm{TiO}_{2}$ nanoparticles on mechanical properties and ionic conductivity of solvent-free polymer electrolytes based on porous $\mathrm{P}(\mathrm{VdF}-\mathrm{HFP}) /$ P(EO-EC) membranes. J Power Sources 162(2):1304-1311

Jeyapandian M, Lavina S, Thayumanasundararam S, Ohno H, Negro E, Noto VD (2010) New hybrid inorganic-organic polymer electrolytes based on $\mathrm{Zr}(\mathrm{O}(\mathrm{CH}(2))(3) \mathrm{CH}(3))(4)$, glycerol and EMIm-TFSI ionic liquid. J Power Sources 195(1):341-353

Ji X, Lee KT, Nazar LF (2009) A highly ordered nanostructured carbon-sulphur cathode for lithium-sulfur batteries. Nat Mater 8(6):500-506

Jin B, Kim J-U, Gu H-B (2003) Electrochemical properties of lithium-sulfur batteries. J Power Sources 117(1-2):148-152

Jow TR, Xu K, Zhang SS, Ding MS (2005) Nonflammable nonaqueous electrolyte and non-aqueous electrolyte cells comprising the same. US Patent 6,924,061

Kao H-M, Chen C-L (2004) An organic-inorganic hybrid electrolyte derived from self-assembly of a poly(ethylene oxide)-poly(propylene oxide)-poly(ethylene oxide) triblock copolymer. Angew Chem Int Ed 43(8):980-984

Kao H-M, Chao S-W, Chang P-C (2006) Multinuclear solid-state NMR, self-discussion coefficients, differential scanning calorimetry, and ionic conductivity of solid organic-inorganic hybrid electrolytes based on PPG-PEG-PPG diamine, siloxane, and lithium perchlorate. Macromolecules 39(3):1029-1040

Katakabe T, Kawano R, Watanabe M (2007) Acceleration of redox diffusion and charge-transfer rates in an ionic liquid with nanoparticle addition. Electrochem Solid State Lett 10(6):F23-F25

Kerr JB, Han YB, Liu G, Reeder C, Xie J, Sun X (2004) Interfacial behavior of polymer electrolytes. Electrochim Acta 50(2-3): 235-242

Klein RJ, Zhang S, Dou S, Jones BH, Colby RH, Runt J (2006) Modeling electrode polarization in dielectric spectroscopy: ion mobility and mobile ion concentration of single-ion polymer electrolytes. J Chem Phys 124(14):144903

Kobayashi T, Yamada A, Kanno R (2008) Interfacial reactions at electrode/electrolyte boundary in all solid-state lithium battery using inorganic solid electrolyte, thio-LISICON. Electrochim Acta 53(15):5045-5050

Kotobuki M, Suzuki Y, Munakata H, Kanamura K, Sato Y, Yamamoto K, Yoshida T (2010a) Compatibility of $\mathrm{LiCoO}(2)$ and $\mathrm{LiMn}(2) \mathrm{O}(4)$ cathode materials for $\mathrm{Li}(0.55) \mathrm{La}(0.35) \mathrm{TiO}(3)$ electrolyte to fabricate all-solid-state lithium battery. J Power Sources 195(17):5784-5788

Kotobuki M, Munakata H, Kanamura K, Sato Y, Yoshida T (2010b) Compatibility of $\mathrm{Li}(7) \mathrm{La}(3) \mathrm{Zr}(2) \mathrm{O}(12)$ solid electrolyte to allsolid-state battery using $\mathrm{Li}$ metal anode. J Electrochem Soc 157(10):A1076-A1079

Kotobuki M, Suzuki Y, Munakata H, Kanamura K, Sato Y, Yamamoto K, Yoshida T (2010c) Fabrication of three-dimensional battery using ceramic electrolyte with honeycomb structure by sol-gel process. J Electrochem Soc 157(4):A493-A498

Krawiec W, Scanlon LG, Fellner JP, Vaia RA, Vasudevan S, Giannelis EP (1995) Polymer nanocomposites-a new strategy for synthesizing solid electrolytes for rechargeable lithium batteries. J Power Sources 54(2):310-315

Lane GH, Best AS, MacFarlane DR, Hollenkamp AF, Forsyth M (2010) An azo-spiro mixed ionic liquid electrolyte for lithium metalLiFePO(4) batteries. J Electrochem Soc 157(7):A876-A884

Lee JS, Quan ND, Hwang JM, Bae JY, Kim H, Cho BW, Kim HS, Lee $\mathrm{H}$ (2006) Ionic liquids containing an ester group as potential electrolytes. Electrochem Commun 8(3):460-464

Lee YM, Seo JE, Lee YG, Lee SH, Cho KY, Parka J-K (2007) Effects of triacetoxyvinylsilane as SEI layer additive on electrochemical performance of lithium metal secondary battery. Electrochem Solid State Lett 10(9):A216-A219

Lewandowski A, Swiderska-Mocek A (2009) Ionic liquids as electrolytes for Li-ion batteries - an overview of electrochemical studies. J Power Sources 194(2):601-609

Lewandowski A, Swiderska-Mocek A (2010) Lithium-metal potential in $\mathrm{Li}(+)$ containing ionic liquids. $\mathrm{J}$ Appl Electrochem 40(3):515-524

Liao K-S, Sutto TE, Andreoli E, Ajayan P, McGrady KA, Curran SA (2010) Nano-sponge ionic liquid-polymer composite electrolytes for solid-state lithium power sources. J Power Sources 195(3):867-871

Liu H, Liu Y, Li J (2010) Ionics liquids in surface electrochemistry. Phys Chem Chem Phys 12(8):1685-1697

Luo J-Y, Cui W-J, He P, Xia Y-Y (2010) Raising the cycling stability of aqueous lithium-ion batteries by eliminating oxygen in the electrolyte. Nat Chem 2(9):760-765

Mandal BK, Padhi AK, Shi Z, Chakraborty S, Filler R (2006) Thermal runaway inhibitors for lithium battery electrolytes. J Power Sources 161(2):1341-1345

Martha SK, Markevich E, Burgel V, Salitra G, Zinigrad E, Markovsky B, Sclar H, Pramovich Z, Heik O, Aurbach D, Exnar I, Buqa H, Drezen T, Semrau G, Schmidt M, Kovacheva D, Salyski N (2009) A short review on surface chemical aspects of Li batteries: a key for good performance. J Power Sources 189(1):288-296

Matoba Y, Ikeda Y, Kohjiya S (2002) Ionic conductivity and mechanical properties of polymer networks prepared from high molecular weight branched poly(oxyethylene)s. Solid State Ionics 147(3-4):403-409

Mazor H, Golodnitsky D, Peled E, Wieczorek W, Scrosati B (2008) Search for a single-ion-conducting polymer electrolyte: combined effect of anion trap and inorganic filler. J Power Sources 178(2):736-743

Mei A, Jiang Q-H, Lin Y-H, Nan C-W (2009) Lithium lanthanum titanium oxide solid-state electrolyte by spark plasma sintering. J Alloys Compounds 486(1-2):871-875

Menkin S, Golodnitsky D, Peled E (2009) Artificial solid-electrolyte interphase (SEI) for improved cycleability and safety of lithiumion cells for EV applications. Electrochem Commun 11(9): 1789-1791

Mikhaylik YV, Akridge JR (2003) Low temperature performance of $\mathrm{Li} / \mathrm{S}$ batteries. J Electrochem Soc 150(3):A306-A311

Miller TJ (2009) Electrical Energy Storage for Vehicles: Targets and Metrics, Ford Motor Company

Moganty SS, Baltus RE, Roy D (2009) Electrochemical windows and impedance characteristics of $[\operatorname{Bmim}(+)][\mathrm{BF}(4)(-)]$ and $[\mathrm{Bdmim}(+)][\mathrm{BF}(4)(-)]$ ionic liquids at the surfaces of $\mathrm{Au}, \mathrm{Pt}$, Ta and glassy carbon electrodes. Chem Phys Lett 483(1-3):90

Moganty SS, Jayaprakash N, Nugent JL, Shen J, Archer LA (2010) Ionic-liquid-tethered nanoparticles: hybrid electrolytes. Angew Chem Int Ed 49(48):9158-9161 
Monroe C, Newman J (2005) The impact of elastic deformation on deposition kinetics at lithium/polymer interfaces. J Electrochem Soc 152(2):A396-A404

Morita M, Niida Y, Yoshimoto N, Adachi K (2005) Polymeric gel electrolyte containing alkyl phosphate for lithium-ion batteries. J Power Sources 146(1-2):427-430

Nakagawa H, Izuchi S, Kuwana K, Nukuda T, Aihara Y (2003) Liquid and polymer gel electrolytes for lithium batteries composed of room-temperature molten salt doped by lithium salt. J Electrochem Soc 150(6):A695-A700

Niitani T, Amaike M, Nakano H, Dokko K, Kanamura K (2009) Starshaped polymer electrolyte with microphase separation structure for all-solid-state lithium batteries. $\mathrm{J}$ Electrochem Soc 156(7):A577-A583

Nugent JL, Moganty SS, Archer LA (2010) Nanoscale organic hybrid electrolytes. Adv Mater 22(33):3677

Oesten R, Heider U, Schmidt M (2002) Advanced electrolytes. Solid State Ionics 148(3-4):391-397

Ohno H (2005) Electrochemical aspects of ionic liquids. John Wiley \& Sons, Inc., New Jersey

Ohta N, Takada K, Zhang L, Ma R, Osada M, Sasaki T (2006) Enhancement of the high-rate capability of solid-state lithium batteries by nanoscale interfacial modification. Adv Mater 18(17):2226

Panero S, Scrosati B, Sumathipala HH, Wieczorek W (2007) Dualcomposite polymer electrolytes with enhanced transport properties. J Power Sources 167(2):510-514

Park G, Nakamura H, Lee Y, Yoshio M (2009) The important role of additives for improved lithium ion battery safety. J Power Sources 189(1):602-606

Patil A, Patil V, Shin DW, Choi J-W, Paik D-S, Yoon S-J (2008) Issues and challenges facing rechargeable thin film lithium batteries. Mater Res Bull 43(8-9):1913-1942

Piszcz M, Marzantowicz M, Plewa-Marczewska A, Zukowska GZ, Zalewska A, Pietrzykowski A, Siekierski M (2010) Hybrid polymeric electrolyte based on methylalumoxane. J Power Sources 195(22):7495-7505

Popall M, Andrei M, Kappel J, Kron J, Olma K, Olsowski B (1998) ORMOCERS as inorganic-organic electrolytes for new solid state lithium batteries and supercapacitors. Electrochim Acta 43(10-11):1155-1161

Raghaven P, Choi JW, Ahn JH, Cheruvally G, Chauhan GS, Ahn HJ, Nah C (2008) Novel electrospun poly(vinylidene fluoride-cohexafluoropropylene)-in situ $\mathrm{SiO}_{2}$ composite membrane-based polymer electrolyte for lithium batteries. J Power Sources 184(2):437-443

Reddy MJ, Chu PP, Kumar JS, Rao UVS (2006) Inhibited crystallization and its effect on conductivity in a nano-sized $\mathrm{Fe}$ oxide composite PEO solid electrolyte. J Power Sources 161(1):535-540

Rosso M, Gobron T, Brissot C, Chazalviel J-N, Lascaud S (2001) Onset of dendritic growth in lithium/polymer cells. J Power Sources 97-98(SI):804-806

Rupp B, Schmuck M, Balducci A, Winter M, Kern W (2008) Polymer electrolyte for lithium batteries based on photochemically crosslinked poly(ethylene oxide) and ionic liquid. Eur Polym J 44(9):2986-2990

Ryu HS, Ahn HJ, Kim KW, Ahn JH, Lee JY, Cairns EJ (2005) Selfdischarge of lithium-sulfur cells using stainless-steel currentcollectors. J Power Sources 140(2):365-369

Ryu HS, Ahn HJ, Kim KW, Ahn JH, Cho KK, Nam TH, Kim JU, Cho GB (2006a) Discharge behavior of lithium/sulfur cell with TEGDME based electrolyte at low temperature. J Power Sources 163(1):201-206

Ryu HS, Ahn HJ, Kim KW, Ahn JH, Lee JY (2006b) Discharge process of $\mathrm{Li} / \mathrm{PVdF} / \mathrm{S}$ cells at room temperature. J Power Sources 153(2):360-364
Sakuda A, Kitaura H, Hayashi A, Tadanaga K, Tatsumisago M (2008) Improvement of high-rate performance of all-solid-state lithium secondary batteries using $\mathrm{Li}-\mathrm{CoO}(2)$ coated with $\mathrm{Li}(2))-\mathrm{SiO}(2)$ glasses. Electrochem Solid State Lett 11(1):A1-A3

Schaefer JL, Moganty SS, Yanga DA, Archer LA (2011) Nanoporous hybrid electrolytes. J Mat Chem 21(27):10094-10101

Scrosati B, Garche J (2010) Lithium batteries: status, prospects and future. J. Power Sources 195(9):2419-2430

Seki S, Kobayashi Y, Miyashiro H, Ohno Y, Usami A, Mita Y, Kihira N, Watanabe M, Terada N (2006) Lithium secondary batteries using modified-imidazolium room-temperature ionic liquid. J Phys Chem B 110(21):10228-10230

Seki S, Mita Y, Tokuda H, Ohno Y, Kobayashi Y, Usami A, Watanabe M, Terada N, Miyashiro N (2007) Effects of alkyl chain in imidazolium-type room-temperature ionic liquids as lithium secondary battery electrolytes. Electrochem Solid State Lett 10(10):A237-A240

Shigematsu Y, Ue M, Yamaki J-i (2009) Thermal behavior of charged graphite and $\mathrm{Li}(\mathrm{x}) \mathrm{CoO}(2)$ in electrolytes containing alkyl phosphate for lithium-ion cells. J Electrochem Soc 156(3):A176-A180

Shim EG, Nam TH, Kim JG, Kim HS, Moon SI (2009) Effects of trioctyl phosphate and cresyl diphenyl phosphate as flameretarding additives for Li-ion battery electrolytes. Met Mater Int 15(4):615-621

Shin JH, Cairns EJ (2008) N-methyl-(n-butyl)pyrrolidinium bis (trifluoromethanesulfonyl)imide-LiTFSI-poly(ethylene glycol) dimethyl ether mixture as a $\mathrm{Li} / \mathrm{S}$ cell electrolyte. J Power Sources 177(2):537-545

Singh M, Odusanya O, Wilmes GM, Eitouni HB, Gomez ED, Patel AJ, Chen VL, Park MJ, Fragouli P, Iatrou H, Hadjichristidis N, Cookson D, Balsara NP (2007) Effect of molecular weight on the mechanical and electrical properties of bock copolymer electrolytes. Macromolecules 40(13):4578-4585

Song S-W, Baek S-W (2009) Silane-derived SEI stabilization on thinfilm electrodes of nanocrystalline $\mathrm{Si}$ for lithium batteries. Electrochem Solid State Lett 12(2):A23-A27

Syzdek J, Armand M, Gizowska M, Marcinek M, Sasim E, Szafran M, Wieczorek W (2009) Ceramic-in-polymer versus polymer-inceramic polymeric electrolytes - a novel approach. J Power Sources 194(1):66-72

Takahara H, Tabuchi M, Takeuchi T, Kageyama H, Ide J, Handa K, Kobayashi Y, Kurisu Y, Kondo S, Kanno R (2004) Application of lithium metal electrolytes to all-solid-state lithium secondary batteries using $\mathrm{Li}_{3} \mathrm{PO}_{4}-\mathrm{Li}_{2} \mathrm{~S}-\mathrm{SiS}_{2}$ glass. $\mathrm{J}$ Electrochem Soc 151(9):A1309-A1313

Tarascon J-M, Gozdz AS, Schmutz C, Shokoohi F, Warren PC (1996) Performance of Bellcore's plastic rechargeable Li-ion batteries. Solid State Ionics 86(8):49-54

Tenhaeff W, Yu X, Hong K, Perry KA, Dudney NJ (2011) Ionic transport across interfaces of solid glass and polymer electrolytes for lithium ion batteries. J Electrochem Soc 158(10):A1143-A1149

Terada Y, Yasaka K, Nishikawa F, Konishi T, Yoshio M, Nakai I (2001) In situ XAFS analysis of $\mathrm{Li}(\mathrm{Mn}, \mathrm{M})(2) \mathrm{O}-4$ (M = Cr, Co, $\mathrm{Ni}) 5 \mathrm{~V}$ cathode materials for lithium-ion secondary batteries. J Solid State Chem 156(2):286-291

Todorov YR, Hideshima Y, Noguchi H, Yoshio M (1999) Determination of theoretical capacity of metal-ion doped $\mathrm{LiMn}_{2} \mathrm{O}_{4}$ as the positive electrode in $\mathrm{Li}$-ion batteries. J Power Sources 77(2):198-201

Tokuda H, Hayamizu K, Ishii K, Abu Bin Hasan Susan M, Watanabe M (2004) Physiochemical properties and structures of room temperature ionic liquids. 1. Variation of anionic species. J Phys Chem B 108(42):16593-16600

Tsuda T, Kondo K, Tomioka T, Takahashi $\mathrm{Y}$, Matsumoto $\mathrm{H}$, Kuwabata S, Hussey CL (2011) Angew Chem Int Ed 50(6): $1310-1313$ 
Uchiyama R, Kusagawa K, Hanai K, Imanishi N, Hirano A, Takeda Y (2009) Development of dry polymer electrolytes based on polyethylene oxide with co-bridging agent crosslinked by electron beam. Solid State Ionics 180(2-3):205-211

Valencia H, Kohyama M, Tanaka S, Matsumoto H (2002) Ab initio study of EMIM-BF(4) crystal interaction with a Li (100) surface as a model for ionic liquid/Li interfaces in $\mathrm{Li}$-ion batteries. J Chem Phys 131(24):244705

Verma P, Maire P, Novak P (2010) A review of the features and analyses of the solid electrolyte interphase in Li-ion batteries. Electrochim Acta 55(22):6332-6341

Walden P (1914) Bull Acad Imper Sci (St. Petersburg) 1800

Walls HJ, Riley MW, Singhal RR, Spontak RJ, Fedkiw PS, Khan SA (2003) Nanocomposite electrolyte with fumed silica and hectorite clay networks: passive versus active fillers. Adv Funct Mater 13(9):710-717

Wang Y, Zhou H (2010) A lithium-air battery with a potential to continuously reduce $\mathrm{O}(2)$ from air for delivering energy. J Power Sources 195(1):358-361

Wang X, Yasukawa E, Kasuya S (2001) Nonflammable trimethyl phosphate solvent-containing electrolytes for lithium-ion batteries-I. Fundamental properties. J Electrochem Soc 148(10): A1058-A1065

Wang J, Liu L, Ling Z, Yang J, Wan C, Jiang C (2003) Polymer lithium cells with sulfur composites as cathode materials. Electrochim Acta 48(13):1861-1867

Wang J, Wang Y, He X, Ren J, Jiang C, Wan C (2004a) Electrochemical characteristics of sulfur composite cathode materials in rechargeable lithium batteries. J Power Sources 138(1-2):271-273

Wang P, Zakeeruddin SM, Comte P, Exnar I, Gratzel M (2004b) Ionic liquid-based electrolytes with silica nanopoarticles for quasisolid-state dye-sensitized solar cells. J Am Chem Soc 125(5): $1166-1167$

Wang WK, Wang Y, Huang YQ, Huang CJ, Yu ZB, Zhang H, Wang $A B$, Yuan KG (2010a) The electrochemical performance of lithium-sulfur batteries with $\mathrm{LiClO}(4)$ DOL/DME electrolyte. J Appl Electrochem 40(2):321-325

Wang W, Liu W, Tudryn GJ, Colby RH, Winey KI (2010b) Multilength scale morphology of poly(ethylene oxide)-based sulfonate ionomers with alkali cations at room temperature. Macromolecules 43(9):4223-4229

Wasserschied P, Welton T (2003) Ionic liquids in synthesis. Wiley$\mathrm{VCH}$, Weinhiem

Welton T (1999) Room-temperature ionic liquids. Solvents for synthesis and catalysis. Chem Rev 99(8):2071-2083
Wilkes JS, Zaworotko MJ (1992) Air and water stable 1-ethyl-3methylimidazolim based ionic liquids. J Chem Soc Chem Commun 13:965-967

Xie J, Imanishi N, Zhang T, Hirano A, Takeda Y, Yamamoto O, Zhao XB, Cao GS (2010) Electrochemical performance of all-solidstate $\mathrm{Li}$ batteries based $\operatorname{LiMn}(0.5) \mathrm{Ni}(0.5) \mathrm{O}(2)$ cathode and NASICON-type electrolyte. J Power Sources 195(24):83418346

$\mathrm{Xu} \mathrm{K} \mathrm{(2004)} \mathrm{Nonaqueous} \mathrm{liquid} \mathrm{electrolytes} \mathrm{for} \mathrm{lithium-based}$ rechargeable batteries. Chem Rev 104(10):4303-4417

Xu MQ, Li WS, Zuo XX, Liu JS, Xu X (2007) Performance improvement of lithium ion battery using PC as a solvent component and BS as an SEI forming additive. J Power Sources 174(2):705-710

Xu F, Dudney NJ, Veith GM, Kim Y (2010) Properties of lithium phosphorus oxynitride (Lipon) for 3D solid-state lithium batteries. J Mater Res 25(8):1507-1515

Yamin H, Gorenshtein A, Penciner J, Sternberg Y, Peled E (1988) Lithium sulfur battery-oxidation reduction mechanisms of polysulfides in THF solutions. J Electrochem Soc 135(5): $1045-1048$

Yao W, Zhang Z, Gao J, Li J, Xu J, Wang Z, Yang Y (2009) Vinyl ethylene sulfite as a new additive in propylene carbonate-based electrolyte for lithium ion batteries. Energy Environ Sci 2(10):1102-1108

Yoshio M, Brodd RJ, Kozawa A (eds) (2009) Lithium-ion batteries: science \& technologies. Springer, Berlin

Yu X, Bates JB, Jellison GE Jr, Hart FX (1997) A stable thin-film lithium electrolyte: lithium phosphorus oxynitride. J Electrochem Soc 144(2):524-532

Zhang SS (2006) A review on electrolyte additive for lithium-ion batteries. J Power Sources 162(2):1379-1394

Zhang HP, Xia Q, Wang B, Yang LC, Wu YP, Sun DL, Gan CL, Luo HJ, Bebeda AW, van Ree T (2009) Vinyl-tris-(methoxydiethoxy)silane as an effective and ecofriendly flame retardant for electrolytes in lithium ion batteries. Electrochem Commun 11(3):526-529

Zhao Y, Van der Noot T (1997) Electrodeposition of aluminum from nonaqueous organic electrolytes systems and room temperature molten salts. Electrochim Acta 42(1):3-13

Zhou DY, Li WS, Tan CL, Zuo XX, Huang HJ (2008) Cresyl diphenyl phosphate as flame retardant additive for lithium-ion batteries. J Power Sources 184(2):589-592

Zhou H, Wang Y, Li H, He P (2010) The development of a new type of rechargeable batteries based on hybrid electrolytes. Chem Sus Chem 3(9):1009-1019 